\title{
Evaluation of Physicochemical Properties of Provitamin K3 Derived Benzo[a]Phenoxazine as a Photosensitizer
}

\author{
Suprabha S. Sahoo, ${ }^{1}$ Dattatray Chadar, ${ }^{1}$ Manilal Murmu, ${ }^{2,3}$ Priyabrata Banerjee, ${ }^{2,3}$ Sunita Salunke-Gawali ${ }^{1, *}$ and R. J. Butcher ${ }^{4}$
}

\begin{abstract}
Three benzo[ $\alpha]$ phenoxazine based photosensitizers known as 10-Chloro-6-methyl-5H benzo[ $\alpha]$ phenoxazin-5-one (BPO-Cl), 6-methyl-5H-benzo[ $\alpha]$ phenoxazin-5-one (BPO), and 6-methyl-5H-benzo[ $\alpha]$ phenothiazin-5-one (BPT) synthesized from provitamin K3 were used as photosensitizers to fabricate a dye-sensitized solar cells (DSSC) device. The inbuilt intra-molecular charge transfer (ICT), favorable $\pi-\pi$ interaction, planar shape, and compatible redox nature with appropriate frontier molecular orbitals (HOMO and LUMO) alignment are the significant physicochemical characteristics of benzo[ $\alpha]$ phenoxazine moiety that rationalize to become an efficient photosensitizer. Thus, the bare benzo[ $\alpha]$ phenoxazine dyes without any efficient anchor and donor group are evaluated here with their intrinsic chemical behavior for efficient precursors in various energy transferring material. The intramolecular charge transfer occurring through aromatic rings bridged by two heteroatoms $(\mathrm{O} / \mathrm{S}$ and $\mathrm{N})$ is tunable with DFT analysis and single-crystal XRD data. The characteristic solar cell parameters show that chlorine substitution enhances the open-circuit voltage $\left(V_{o c}\right)$ from $0.53 \mathrm{~V}$ in $\mathrm{BPO}$ to $0.56 \mathrm{~V}$ in $\mathrm{BPO}-\mathrm{Cl}$. A noticeable enhancement in short-circuit current density $\left(J_{s c}\right)$ nearly fivefold is observed for BPO dye compared to its thio-substituted BPT unit. The substitution of chlorine reduces the recombination rate in the device studied from electrochemical impedance spectroscopy. Thus BPO template is an excellent precursor to tailor various D/A groups to produce effective photosensitizer evaluated by physicochemical properties tunable with several optoelectrical, structural, morphological, and electrochemical analyses.
\end{abstract}

Keywords: Benzo[$[\alpha]$ phenoxazine; Recombination resistance; Physicochemical properties; Naphthoquinone; Photosensitizer; DSSC.

Received: 8 January 2021; Accepted: 25 January 2021.

Article type: Research article.

\section{Introduction}

The application of organic dyes in dye-sensitized solar cells (DSSC), ${ }^{[1]}$ organic solar cells (OSCs), ${ }^{[2]}$ organic light-emitting diodes (OLEDs), sensors, ${ }^{[3,4]}$ storage devices, ${ }^{[5]}$ to attain achievable synthetic targets with desired moieties is one of the highly explored and demanded areas nowadays. Large extinction coefficient, non-toxicity, cost-effectiveness,

\footnotetext{
${ }^{1}$ Department of Chemistry, Savitribai Phule Pune University, Pune 411007, India.

2 Surface Engineering \& Tribology Group, CSIR-Central Mechanical Engineering Research Institute, M.G. Avenue, Durgapur 713209, West Bengal, India.

3 Academy of Scientific and Innovative Research (AcSIR), AcSIR Headquarters CSIR-HRDC Campus, Sector-19, Kamla Nehru Nagar, Ghaziabad, 201002, Uttar Pradesh, India.

${ }^{4}$ Department of Chemistry, Howard University, Washington, D.C, 20059, USA.

*E-mail: sunita.salunke@unipune.ac.in (S. Salunke-Gawali)
}

tunable optical properties, adequate redox nature, and facile molecular engineering are the effective positive attributes of organic dyes over metal-complex based dyes. ${ }^{[6,7]}$ Hence nontoxic, efficiently synthesized organic precursors has been engineered these days to produce several types of effective $D-\pi-A, D-D-\pi-A$, porphyrin, squaraine architecture ${ }^{[8]}$ of dyes by tailoring different donor (D) and acceptor (A) moieties to the organic framework as a central stem. In this context, numerous publications are reported with various organic frameworks like xanthenes ${ }^{[9,10]}$ coumarins, ${ }^{[11-14]}$ squaraine, ${ }^{[15,16]}$ anthracene, ${ }^{[1718]}$ bodipy, ${ }^{[19-21]} e t c$. used in DSSC. However, benzo[ $\alpha]$ phenoxazine dyes are significantly less explored despite their planar shape, favorable $\pi-\pi$ interaction with good intra-molecular charge transfer (ICT); for an efficient DSSC photosensitizer. ${ }^{[22]}$

Photosensitizers are the primary controlling unit of DSSC, so numerous reports are available by varying the functionality of different organic moieties in the photosensitizer. Like benzo $[\alpha]$ phenoxazine molecule, this can 
be functionalized as both donor and $\pi$-linker. However, very few reports are available with phenoxazine moieties, which can perform a dual function as donor and $\pi$-linker in specific $D-\pi$-A dyes such as Tian and his co-workers reported phenoxazine as an efficient donor (D) for DSSC dyes. ${ }^{[23]}$ Similarly, Tan and his team employed two phenoxazine-based dyes where phenoxazine and substituted phenoxazine were used as donor molecule; ${ }^{[24]}$ Wenjun et al. reported phenothiazine as a hole transporting material in organic semiconductor devices and used them as a $\pi$-linker as well as a donor molecule. ${ }^{[25]}$ Further, Tian and his team used phenoxazine unit as both linker and donor moiety, ${ }^{[26]}$ whereas benzo[ $\alpha]$ phenoxazine moieties were used as chromophores for DSSC by Schroder et al. ${ }^{[22]}$ and benzo[ $\left.\alpha\right]$ phenothiazine was used by Bhand et al. as a photosensitizer with Zirconium semiconducting metal oxide. ${ }^{[27]}$ However, benzo[ $\alpha]$ phenoxazine dyes have not yet been explored as photosensitizers with or without any other tailored group. The positive attributes of benzo[ $\alpha]$ phenoxazine over phenoxazine moiety is it's; i) extended absorbance, which can help to harness more solar radiation, ii) extended conjugation with planarity, iii) adequate redox nature, iv) proper alignment of molecular orbitals (HOMO, LUMO), v) inbuilt internal charge transport through the moiety (ICT) and vi) prone to agile molecular engineering with flexible sites for various D/A substitution.

Herein, two benzo[ $\alpha]$ phenoxazine derivatives, namely, 6-methyl-5H-benzo[a]phenoxazin-5-one (BPO), chlorine substituted benzo[ $\alpha]$ phenoxazine that 10-Chloro-6-methyl-5H-benzo[ $\alpha]$ phenoxazin-5-one

(BPO-Cl), and one benzo[ $\alpha]$ phenothiazine molecule such as 6-methyl-5H-benzo[ $\alpha]$ phenothiazin-5-one (BPT) were utilized as photosensitizers with nanoporous $\mathrm{TiO}_{2}$ photoanode prepared through doctor blade technique. A comparative study of all the dyes' physicochemical properties was studied to find out the impact of substitution on the moiety. The detailed morphological, photo-physical, electrochemical, and solar cell characterizations were analyzed, showing chlorine substituted dye (BPO-Cl) is the potential candidate for photosensitization. Furthermore, to evaluate the dye's inherent chemical potentiality, single crystal XRD and DFT analysis were tuned with electrochemical analysis. The primary reason that impedes solar cell parameters like $V_{O C}$ and $J_{S C}$ in the device is the aggregation and lack of efficient donor and anchoring moiety because the charge collection efficiency of these dyes is more than $\sim 99 \%$ means the dyes are quite efficient to absorb the solar radiation and can produce a high amount of charge carrier but are not efficient to separate the charge carriers to generate electricity. Herein, in this study, the addition of simple chlorine substitution manages the recombination mechanism in the device to many folds. This exemplifies an efficient D/A group at the particular sites in the moiety that will enhance the dyes solar cell effectiveness by controlling its recombination dynamics. So to get an efficient photosensitizer with phenoxazine functionality, benzo[ $\alpha]$ phenoxazine is a suitable precursor to being work upon with an adequate D/A group for which all the mandatory physicochemical properties are studied in this investigation.

\section{Experimental section and computational Methods 2.1 Materials}

The Fluorine doped tin oxide (FTOs) were used as a source of conducting glass having sheet resistance $13-18 \Omega / \mathrm{cm}^{2}$ purchased from Sigma Aldrich used in the photoanode preparation. P25 Degussa (Nanoshell LLC, US) was used as a source of titanium nanopowder. The chemicals associated with photoanode and photosensitizer preparation like ethanol (Merck), acetonitrile (Merck), acetylacetone (SRL), ethylcellulose (SRL), and $\alpha$-terpineol (kemphasol) were used as received. Iodine/triiodide solution used as an electrolyte in the device composed of Lithium iodide (SRL, India), iodine(Sigma Aldrich), tert butyl pyridine (ACROS Organics, Belgium) also used directly without any further purification. The synthetic procedure and the characterization of photosensitizer dye with benzo[ $\alpha]$ phenoxazine and benzo[ $\alpha]$ phenothiazine template are available in the previous report. ${ }^{[28]}$

\subsection{Device fabrication}

The device was constructed using a nanocomposite mesoporous $\mathrm{TiO}_{2}$ photoanode as a working electrode prepared by the doctor blade technique with FTO substrate. A compact layer designed from $\mathrm{TiCl}_{3}$ and $\mathrm{NaOH}$ with basic $\mathrm{pH}$ was prepared by the Chemical Bath Deposition (CBD) method. After calcination with $450{ }^{\circ} \mathrm{C}$, a mesoporous uniform layer of $\mathrm{TiO}_{2}$ paste was applied on the compact layer and again annealed at $450{ }^{\circ} \mathrm{C}$ to get the desired photoanode's specific morphology. The detailed synthetic method was reported in our previous paper. ${ }^{[28]}$ The synthetic procedure used for the preparation of $\mathrm{BPO}, \mathrm{BPO}-\mathrm{Cl}$, and BPT is taking place by condensation of provitamin $\mathrm{K} 3$ (2-methyl-1,4-naphthoquinone) with derivatives of 2-aminophenol and 2-aminothiophenol to produce benzo $[\alpha]$ phenoxazine and benzo $[\alpha]$ phenothiazine moiety. Specifically, carbonyl group present on the quinonoid ring, heteroatoms $(\mathrm{O} / \mathrm{S}, \mathrm{N})$ in the form of oxo/thio, and imine group entangled in the moiety can be used extra anchoring sites. In addition to this, the total molecule acts as a $\pi$-donor and a $\pi$-linker due to its very good redox property and efficient intramolecular charge transfer (ICT) through the heteroatoms. One way electron donation property (switching on nature) and $\pi-\pi$ stacking interactions are these dyes' significant characteristics. $\left(\mathrm{I}^{-} / \mathrm{I}_{3}{ }^{-}\right)$used as electrolyte composed of lithium iodide $0.5 \mathrm{M}, 0.05 \mathrm{M}$ iodine, and 0.15 $\mathrm{M}$ tertbutyl pyridine in $100 \mathrm{ml}$ acetonitrile as per laboratory reported method ${ }^{[29]}$ followed by platinum-coated FTOs as the counter electrode. Both the working and counter electrodes were separated through the spacer and connected through the electrolyte to regenerate the dye molecule and maintain 
electron neutrality in the device through charge transport via the electrolyte.

\subsection{Solar cell device characterization}

The absorption and emission spectra were measured with SHIMADZU UV 1650 spectrophotometer from $200 \mathrm{~nm}$ to $600 \mathrm{~nm}$ and JASCO spectrofluorometer FP-8300 between 450 and $700 \mathrm{~nm}$. To get a better insight into the excited state lifetime, the fluorescence lifetime of the samples was measured with a time-correlated single-photon counter (TCSPC) method using a light-emitting diode (nano-LED) excited with $450 \mathrm{~nm}$ by Horiba Fluorolog FL3 (FL-1057) instrument with fast photomultiplier tubes (PMTs). The decay data were analyzed using commercial software given by the Horiba instrument. FT-IR spectra were obtained from BRUKER VERTEX by SHIMADZUFT 8400 Spectrometer between $4000-400 \mathrm{~cm}^{-1}$ by ATR technique. The electrochemical analysis was performed with CHI 6054E Electrochemical Analyser (CHI 660) at a scan rate of 0.1 $0.5 \mathrm{Vs}^{-1}$ in acetonitrile against $\mathrm{Ag} / \mathrm{AgNO}_{3}$ (BAS) as the reference electrode, Platinum disc electrode (CHI102, surface area $\left.0.025 \mathrm{~cm}^{2}\right)$ as working electrode and Platinum wire electrode (CHI115) as the counter electrode at room temperature $\left(26^{\circ} \mathrm{C}\right)$. Before commencing measurement each time, the analyte was deoxygenated by nitrogen purging. Field emission scanning electron microscopy, FESEM, (Carl Zeiss, Merlin Compact), was conducted to study the corresponding photoanode's morphology and elemental composition. Solar cell parameters are checked with a solar simulator in association with Keithley 2420 source meter for current-voltage measurements under 1 Sun. Electrochemical impedance spectroscopy (EIS) was carried out using a two-electrode system between $-1 \mathrm{~Hz}$ to $-10 \mathrm{kHz}$ frequency range to study the electron dynamics in the device under dark conditions.

\subsubsection{The single-crystal XRD data collection}

$\mathrm{X}$-ray quality red crystals of BPO were obtained after evaporation of pure red fraction from the column. Crystals of the appropriate size were chosen for data collection. Data was collected through D8 Venture PHOTON 100 CMOS diffractometer using graphite monochromatized Mo-K $\alpha$ radiation $(\lambda=0.7107 \AA)$ with exposure/frame $=10$ sec for molecule A. The X-ray generator was operated at 50 $\mathrm{kV}$ and $30 \mathrm{~mA}$ for Mo-K $\alpha$ radiation. An initial set of cell constants and orientation matrix were calculated from 24 frames and 60 frames for Mo and $\mathrm{Cu}$ source, respectively. The optimized strategy used for data collection consisted of different $\varphi$ and $\omega$ scans with $0.5^{\circ}$ steps in $\varphi / \omega$. Crystal to detector distance was $5.00 \mathrm{~cm}$ with 512 x 512 pixels/frame, Oscillation/frame $-0.5^{\circ}$, maximum detector swing angle was $-30.0^{\circ}$, beam centered at $(260.2,252.5)$ and in-plane spot width of 1.24 unit. Bruker SAINT Program and Bruker SADABS were employed for data integration and empirical absorption correction for intensity data. The program was integrated into the APEX II package. The data were corrected for Lorentz and polarization effect. The structure was solved by Direct Method using SHELX-97. ${ }^{[30]}$ The final refinement of the structure was performed by full-matrix least-squares techniques with anisotropic thermal data for non-hydrogen atoms on $\mathrm{F}^{2}$. The non-hydrogen atoms were refined anisotropically, whereas the hydrogen atoms were refined at calculated positions as riding atoms with isotropic displacement parameters. Molecular diagrams were generated using ORTEP $3^{[31]}$ and Mercury programs. ${ }^{[32]}$

\subsubsection{Computational Studies}

All the geometrical optimizations were performed by the ORCA program package (Version 2.7.0) employing hybrid B3LYP functional with $T Z V(P)$ and $\mathrm{SV}(\mathrm{P})$ basis set. ${ }^{[33]}$ Following geometry optimization, the time dependant density functional theory (TD-DFT) calculation was performed using Turbomole (V.7.0) with TmoleX interface 4.1.1. ${ }^{[34-37]}$ The COSMO model was used to incorporate the effect of the solvent. Molecular orbitals were plotted by Molekel 4.3 software. In this experimentation, acetonitrile has been used as a solvent. The ORCA program was used to calculate the contributions of molecular orbitals for the organic entities. The highest occupied molecular orbital (HOMO) and lowest unoccupied molecular orbital (LUMO) values were calculated using B3LYP functional to evaluate the electron density at the ground state and excited state. The plots of molecular orbitals were visualized and generated using Molekel 4.3 software. Similarly, to obtain the data's precision and reliability, TD-DFT computations were carried out with oscillatory strength calculations.

\section{Results and discussion}

\subsection{Photosensitizers Characterization}

\subsubsection{Single Crystal XRD analysis of BPO Dye}

ORTEP diagram of BPO (CCDC 2018650) is shown in Fig.1(a). Single crystal X-ray structure data is presented in Table S1 and hydrogen bonding interaction in Table S2. BPO crystallizes in tetragonal space group $P 42 / n$. There are two molecules in the asymmetric unit labelled in Fig.1(b) (A and B). They are deferred primarily by bond distances as well as close contacts with other molecules. Carbonyl distances $\mathrm{C}(14 \mathrm{~B})-\mathrm{O}(2 \mathrm{~B})$ is $1.251 \AA$ while it is longer in $\mathrm{C}(14 \mathrm{~A})-\mathrm{O}(2 \mathrm{~A})$ $(1.249 \AA)$ (Fig.1 (b), Table S3); however, in the range of oxidized form of the naphthoquinones. Longer $\mathrm{C}(1 \mathrm{~A})-\mathrm{O}(1 \mathrm{~A})$ distance $\sim 1.416 \AA$ is observed in one of the asymmetric molecules A. Fig. S1(Supplementary Fig. S1) showed the atoms involved in hydrogen bonding interaction and $\pi-\pi$ stacking interaction. The asymmetric molecules are joined by the $\mathrm{C}-\mathrm{H} \cdots \mathrm{O}$ hydrogen bonding interaction, where the $\mathrm{C}(3)$-methyl is involved in this interaction. Both the asymmetric molecules also showed $\pi-\pi$ stacking interaction; the only difference is the number of carbons taking part in this interaction. Asymmetric molecule A (green) is in the vicinity of four similar molecules (Fig.1(c)), while molecule B is in the vicinity of three similar molecules via $\pi-\pi$ stacking and $\mathrm{C}-\mathrm{H} \cdots \mathrm{O}$ interaction. $\pi-\pi$ stacking of two equivalent symmetry molecules is shown in Fig.1(c), and Fig. S2 is provided in the supplementary information file. Alternate $\pi-\pi$ 


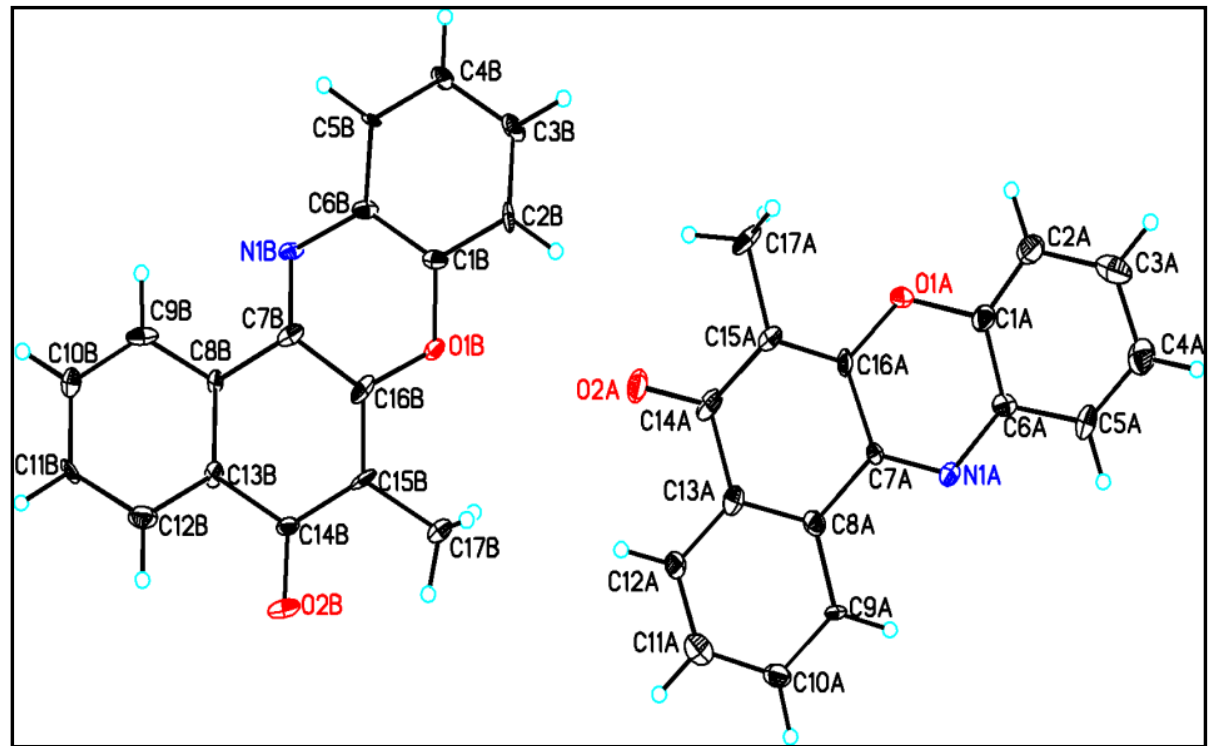

(a)

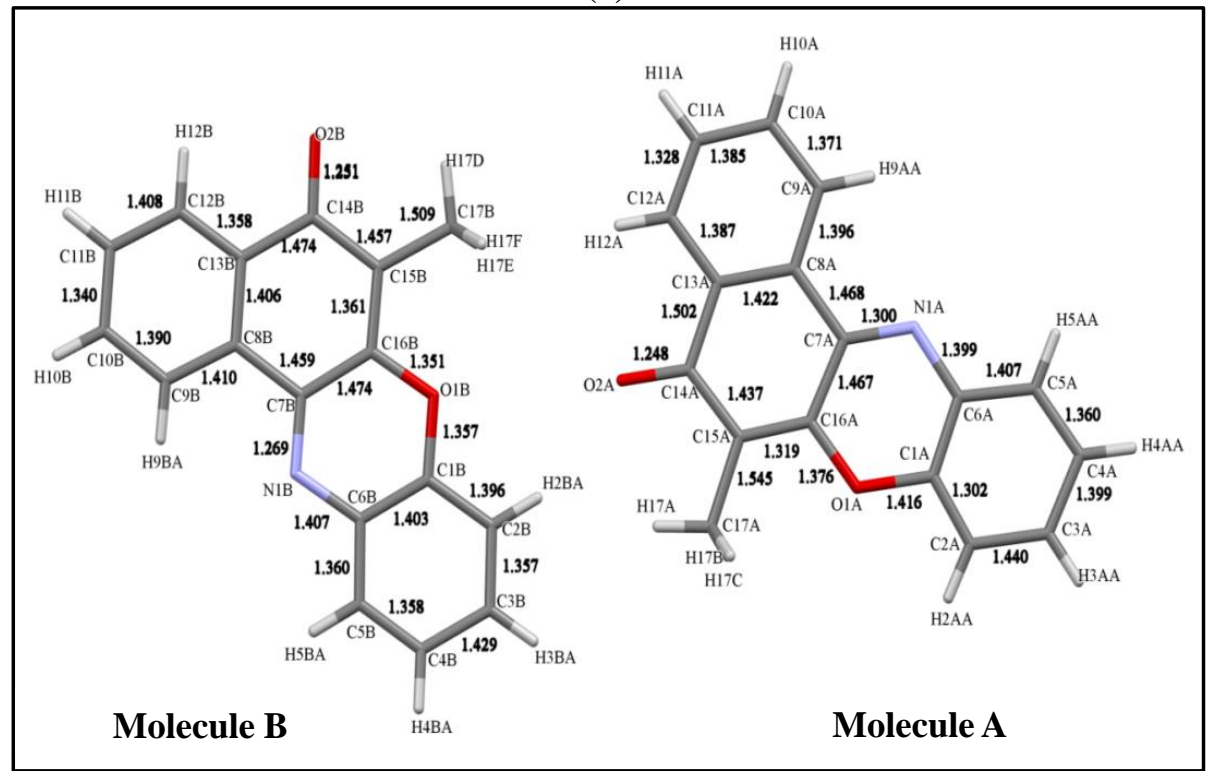

(b)

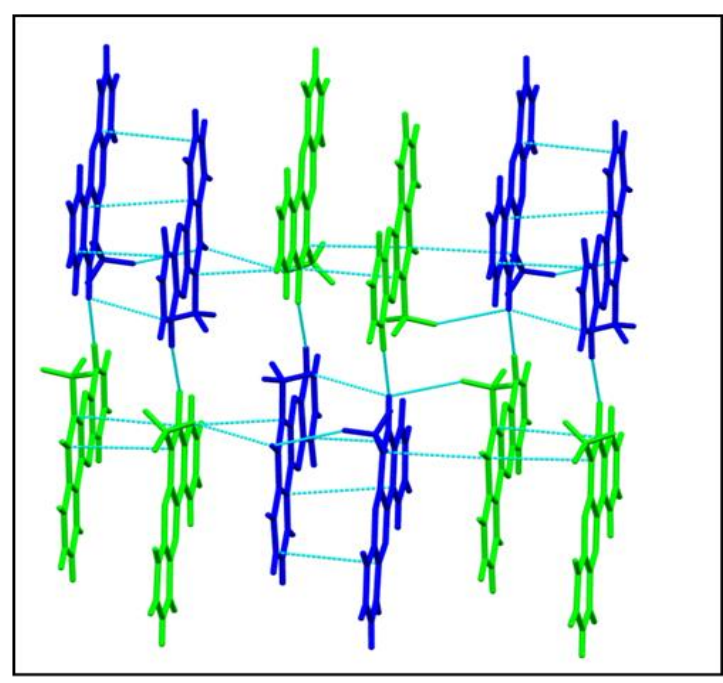

(c)

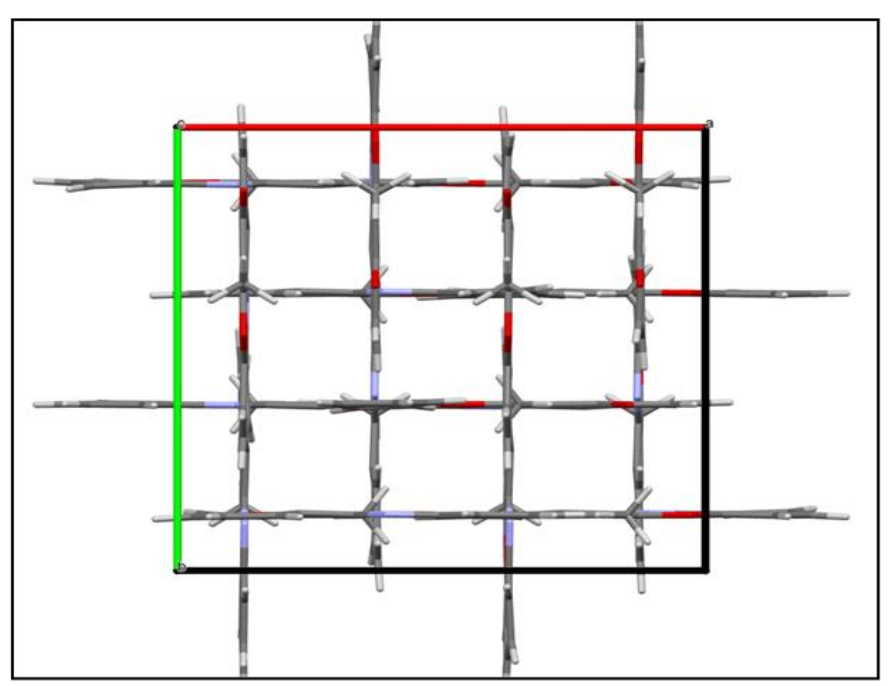

(d)

Fig. 1 (a) ORTEP of BPO dye, the ellipsoids were drawn with a 50\% probability, (b) Bond distances in asymmetric molecules of $\mathrm{BPO},(\mathrm{c}) \pi-\pi$ stacking interaction of symmetry equivalent molecules of BPO, (d) Molecular packing of BPO down c-axis. 


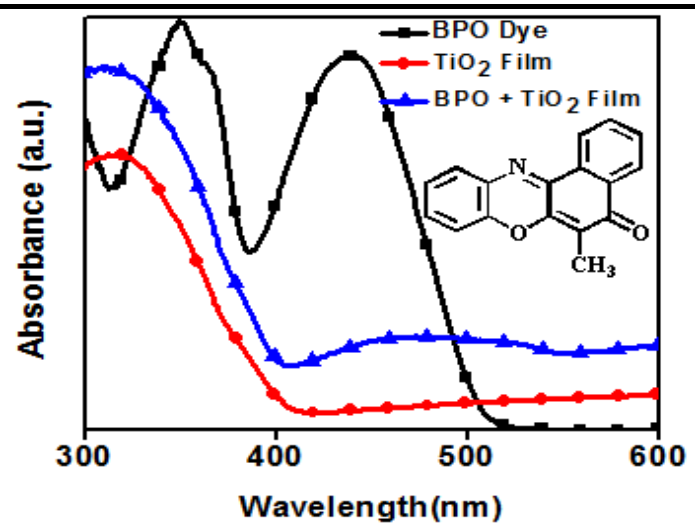

(a)

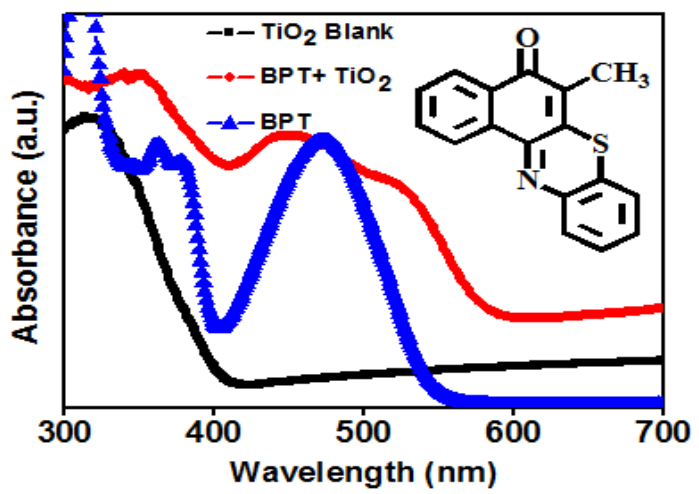

(c)

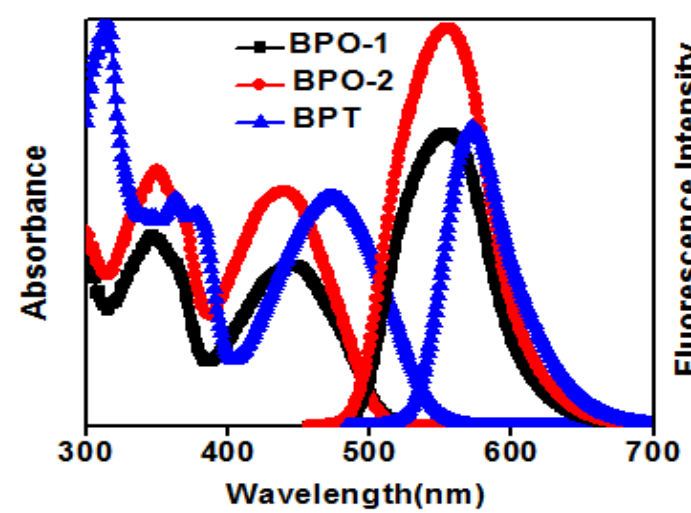

(e)

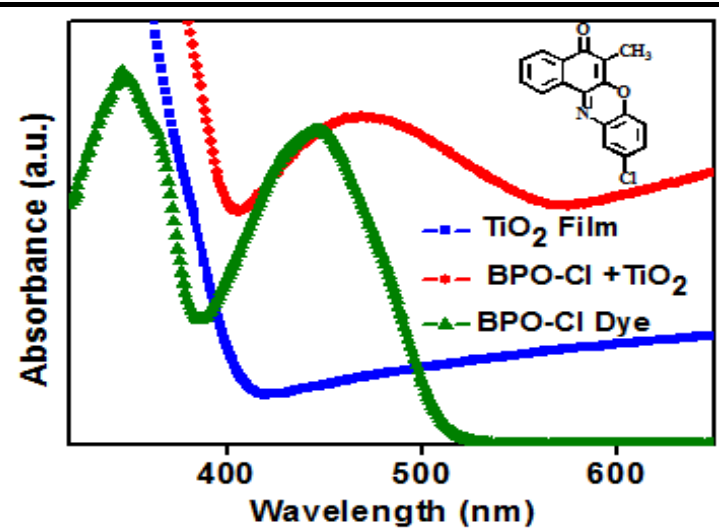

(b)

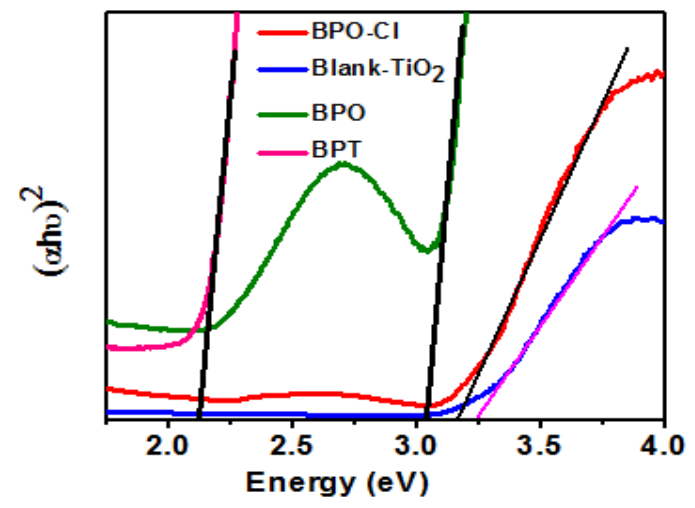

(d)

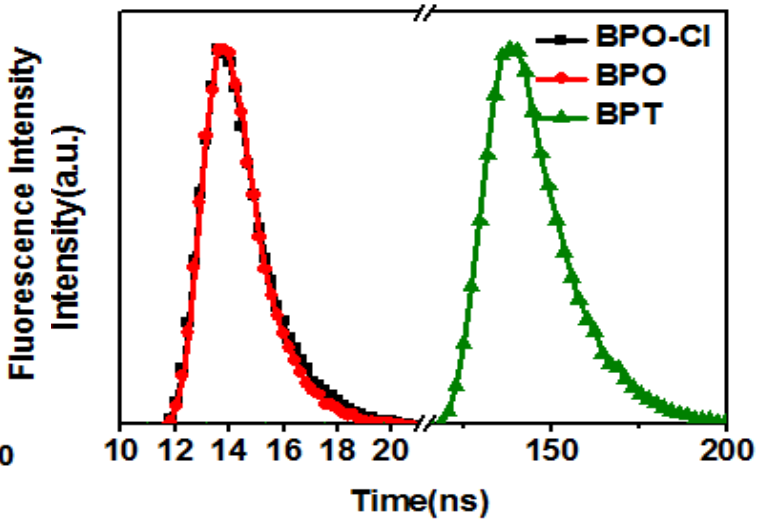

(f)

Fig.2 UV-Visible spectra of dye, $\mathrm{TiO}_{2}$ film, and dye loaded $\mathrm{TiO}_{2}$ film, (a) BPO, (b) BPO-Cl, (c) BPT, (d) shift in conduction band after dye loading, (e) excitation and emission spectra together, (f) Excited state lifetime data of BPO, BPO-Cl and BPT dye.

stacked chain of type A-A and B-B is observed; chains are joined by $\mathrm{C}-\mathrm{H} \cdots \mathrm{O}$ interaction. The molecular packing of $\mathrm{BPO}$ is shown in Fig.1(d). The tetragonal axis lies at the center of the square. The single-crystal XRD data of BPO-Cl and BPT are reported previously. ${ }^{[28]}$ The herring borne architecture of BPO-Cl and butterfly architecture of BPT molecule facilitates reduce aggregation and intermolecular excimer formation ${ }^{[25]}$ of dye molecule and hence capable of enhancing more solar cell efficacy.

\subsubsection{Optical study}

Experimentally measured absorption spectra of BPO, $\mathrm{BPO}-\mathrm{Cl}$, and BPT sensitizers in acetonitrile show two distinctive peaks near $350 \mathrm{~nm}$ and $450 \mathrm{~nm}$, as shown in Fig.2 $(a, b, c)$. In all the three dyes, the absorption band near 440 $\mathrm{nm}$ was attributed to $\mathrm{n}-\pi^{*}$ transition, and the band $\sim 350 \mathrm{~nm}$ was assigned to $\pi-\pi^{*}$ transition. In BPT, the $n-\pi^{*}$ transition is observed at a more extended wavelength region near $474 \mathrm{~nm}$, 
as shown in Fig.2(c). In Fig.2(a, b, c), a comparison between dye loaded film, blank $\mathrm{TiO}_{2}$ film, and basic dye shows a the film, confirming a metal to ligand charge transfer (MLCT). The bathochromic shift towards the visible region of the solar spectrum and hyperchromic shift observed in Fig. 2 ( $a, b, c)$ declares complexation between $\mathrm{TiO}_{2}$ and dye molecule, followed by an adequate amount of dye loading in the film, respectively. The optical band gap of $\mathrm{TiO}_{2}$ photoanode was found to be $3.2 \mathrm{eV}$. After dye loading, the Fermi level shift was very prominent in all three dyes, as shown in Fig.2(d). The compound's optical bandgap after dye loading is $3.04 \mathrm{eV}$ for $\mathrm{BPO}-\mathrm{Cl}, 3.166 \mathrm{eV}$ for $\mathrm{BPO}$, and 2.13 $\mathrm{eV}$ for BPT concerning $\mathrm{TiO}_{2}(3.25 \mathrm{eV})$ before dye loading.

\subsubsection{Emission Spectra}

To study the emission behavior, fluorescence spectra have been recorded between $450 \mathrm{~nm}-700 \mathrm{~nm}$, as shown in Fig.2(e). It shows emission maxima at $558 \mathrm{~nm}, 556 \mathrm{~nm}, 571$ $\mathrm{nm}$ with Stokes shift of $118 \mathrm{~nm}, 105 \mathrm{~nm}$, and $97 \mathrm{~nm}$ for BPO, BPO-Cl, and BPT dyes. The electrical bandgap denoted by $\mathrm{E}_{0-0}$ was calculated to be $2.52 \mathrm{eV}$ for $\mathrm{BPO}$ and $2.49 \mathrm{eV}$ and $2.33 \mathrm{eV}$ for $\mathrm{BPO}-\mathrm{Cl}$, and BPT respectively, which are less than the estimated HOMO-LUMO gap value by TD-DFT calculations showed the later part of this paper. To get a more in-depth insight into photoluminescence spectra (PL spectra), time-dependent fluorescence spectra with TCSPC (time-correlated single-photon count) method was recorded, which shows most extended excited-state lifetime of BPO dye is $1.42 \mathrm{~ns}$ followed by $1.35 \mathrm{~ns}, 1.37 \mathrm{~ns}$ for $\mathrm{BPO}-\mathrm{Cl}$, and BPT respectively in Fig.2(f) and Table 1. The data were fitted with double exponential decay by DAS (Data Analysis software) provided by the same instrument. bathochromic shift of the dye molecule after absorption into

\subsubsection{Electrochemical studies}

The electrochemical analysis unveils the dyes' redox nature, which is the most fundamental parameter to study chemical reactivity and electron transfer parameters. The three-electrode system performed cyclic voltammetry (CV) experiments with a different scan rate of $100-500 \mathrm{mVs}^{-1}$. To find out either of the highest occupied molecular orbital (HOMO) and lowest unoccupied molecular orbital (LUMO) positions as depicted in Fig.3(a). The HOMO and LUMO values were calculated with $E_{0-0}$ values from emission studies vide Fig.2 (e). It can be noticed that BPO possesses the highest bandgap of $2.52 \mathrm{eV}$ among all the three dyes, whereas BPT shows the lowest bandgap of $2.33 \mathrm{eV}$. The optoelectrical study detailed data and electrochemical analysis have been presented in Fig.3(b) and Table 1. It shows the LUMO level of all the three dyes above the fermi level of $\mathrm{TiO}_{2}$ semiconducting metal oxide. The HOMO level is below the work-function of the standard redox potential of iodine/triiodide $(0.35 \mathrm{~V}$ versus Normal Hydrogen Electrode NHE).$^{[38]}$ The difference of $0.9-1.31 \mathrm{eV}$ provides an adequate driving force for dye regeneration in the device. The HOMO levels have been calculated using the formula $\mathrm{HOMO}=$ LUMO- $E_{g}$ (optical bandgap). Again, it is in agreement with chlorine's substitution, and sulfur atom comparatively lowers the HOMO level. ${ }^{[39]}$ In $\mathrm{BPO}-\mathrm{Cl}$, the electron injection efficiency is the lowest, facilitating the fastest electron transfer from LUMO to the conduction band $(\mathrm{CB})$ of the semiconducting metal oxide and hence produces more (Voc and $J s c$ ) solar power conversion efficiency among the three devices.

Table1. Photophysical and electrochemical data of dyes and dye loaded films.

\begin{tabular}{cccccccc}
\hline $\begin{array}{c}\text { Compound } \\
\text { Name }\end{array}$ & $\begin{array}{c}\lambda_{\max } \\
(\mathbf{n m})\end{array}$ & $\boldsymbol{\lambda}_{\mathbf{P L}}(\mathbf{n m})$ & $\begin{array}{c}\text { Stokes } \\
\text { shift(nm) }\end{array}$ & ${ }^{\mathbf{a} \mathbf{E}_{\mathbf{0 - 0}}(\mathbf{e v})}$ & ${ }^{\mathbf{b}} \mathbf{E}_{\text {HOMO }}(\mathbf{e v})$ & $\begin{array}{c}\mathbf{E}_{\text {LUMO }} \\
(\mathbf{e v})\end{array}$ & $\begin{array}{c}\text { Excited-state } \\
\text { lifetime (nm) }\end{array}$ \\
\hline BPO & 440 & 558 & 118 & 2.52 & -5.7 & -3.18 & $1.426 \times 10^{-9}$ \\
BPO- Cl & 451 & 556 & 105 & 2.49 & -6.11 & -3.62 & $1.349 \times 10^{-9}$ \\
BPT & 474 & 571 & 97 & 2.33 & -5.94 & -3.61 & $1.373 \times 10^{-9}$ \\
\hline
\end{tabular}

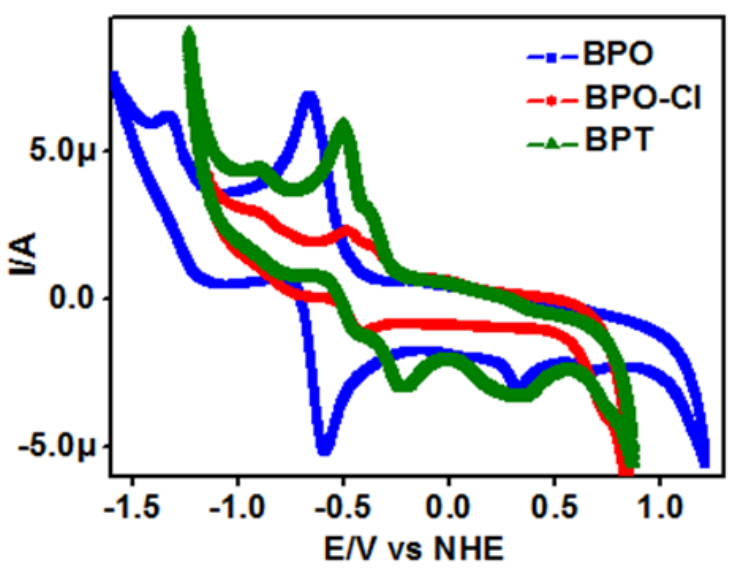

(a)

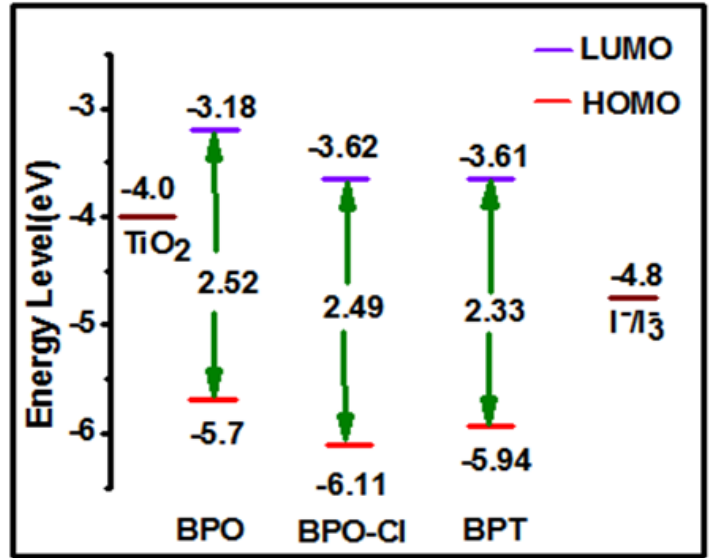

(b)

Fig. 3 (a) Cyclic voltammograms of BPO, BPO-Cl, and BPT dye, (b) $\mathrm{HOMO}-L U M O$ comparison plot with $\mathrm{CB}_{\text {of }} \mathrm{TiO}_{2}$ and redox potential of $\mathrm{I}^{-} / \mathrm{I}_{3}^{-}$. 


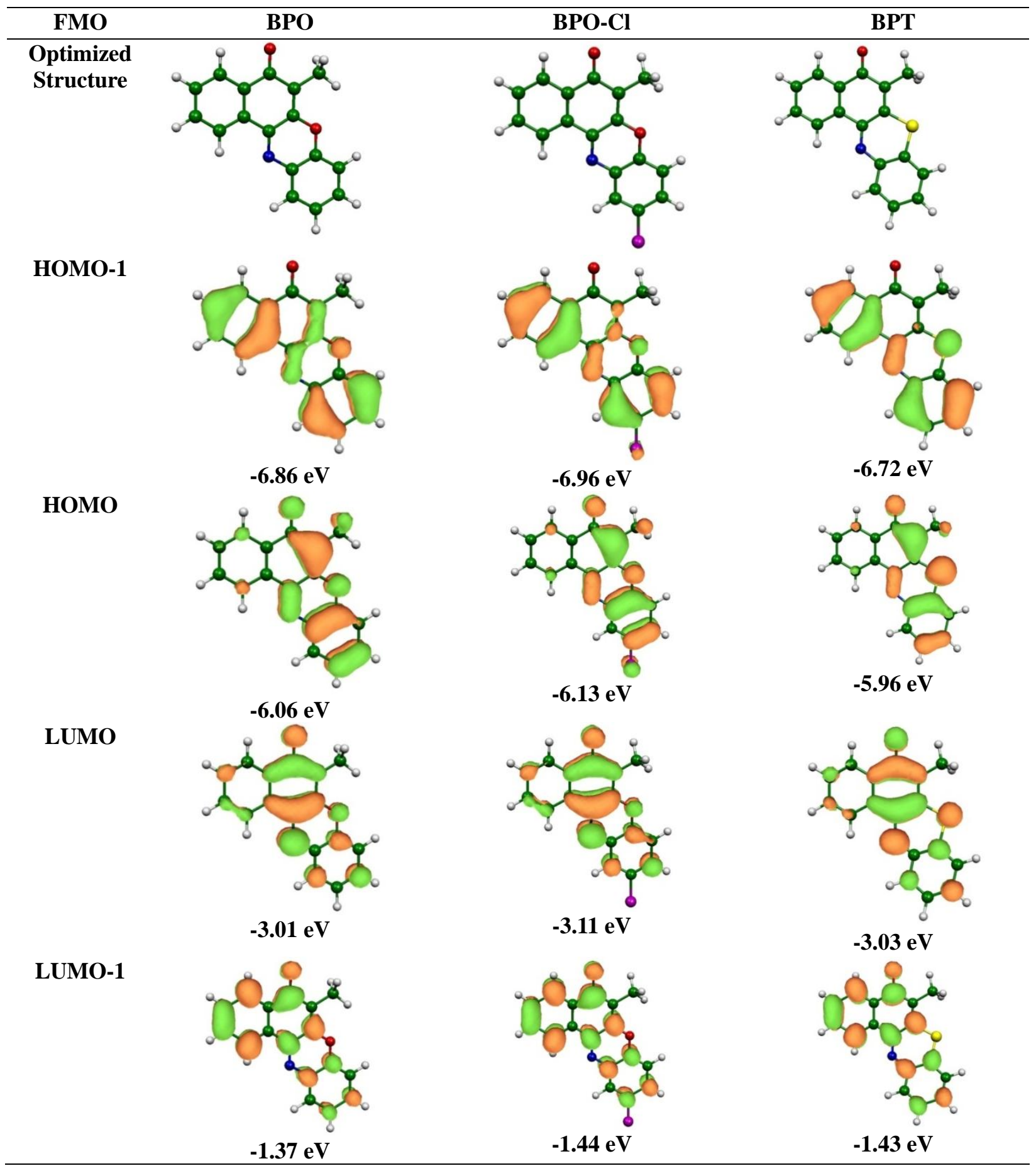

Fig. 4 Optimized geometrical structure and electron density distribution on Frontier molecular orbital plots of BPO, BPO-Cl, and BPT dye. HOMO and LUMO values are depicted at an isovalue of 0.06 .

\subsubsection{Computational studies}

A density functional theory (DFT) study has been carried out to study the structural property, geometry, and probability of electron density on each constituent element. The ease of electron flow in the BPO, $\mathrm{BPO}-\mathrm{Cl}$, and BPT moieties through the heteroatoms is screened from the frontier molecular orbitals (HOMO and LUMO) geometries. The isodensity plots were shown in Fig. 4 with the optimized geometry of the dyes. The HOMO and LUMO orbitals' energy level values are very similar to the values obtained from experimental calculations. A minute difference of \pm 0.5 $\mathrm{eV}$ is observed only in LUMO values of BPO-Cl and BPT dye, whereas other values are exceptionally tunable $( \pm 0.1 \mathrm{eV})$ with the experimental values. An in-depth investigation on HOMO and LUMO values shows electron cloud is highly diffused on the quinonoid and heteroatom-infused aromatic rings in HOMO levels. After absorption of radiation in excitation mode, the electron cloud is moved towards the benzenoid ring and highly dense on the quinonoid ring near carbonyl moiety in the LUMO orbitals. However, in both 


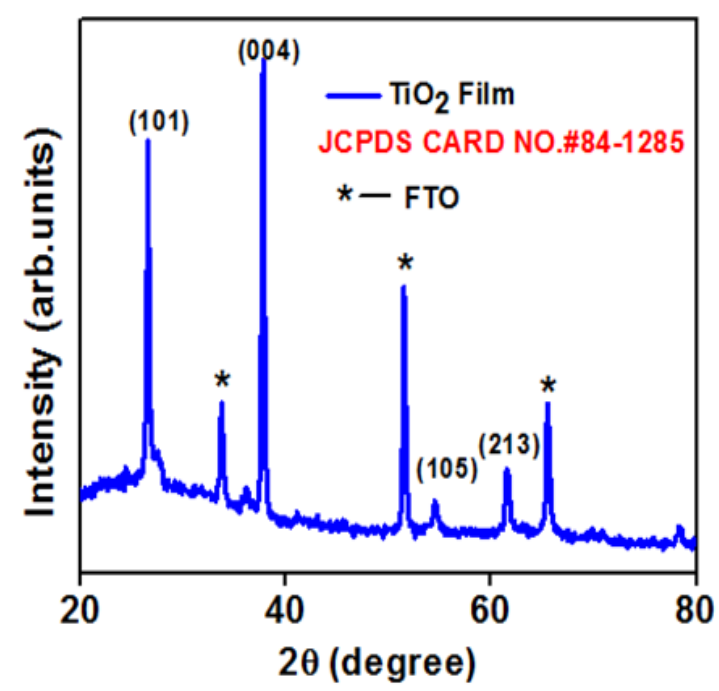

(a)

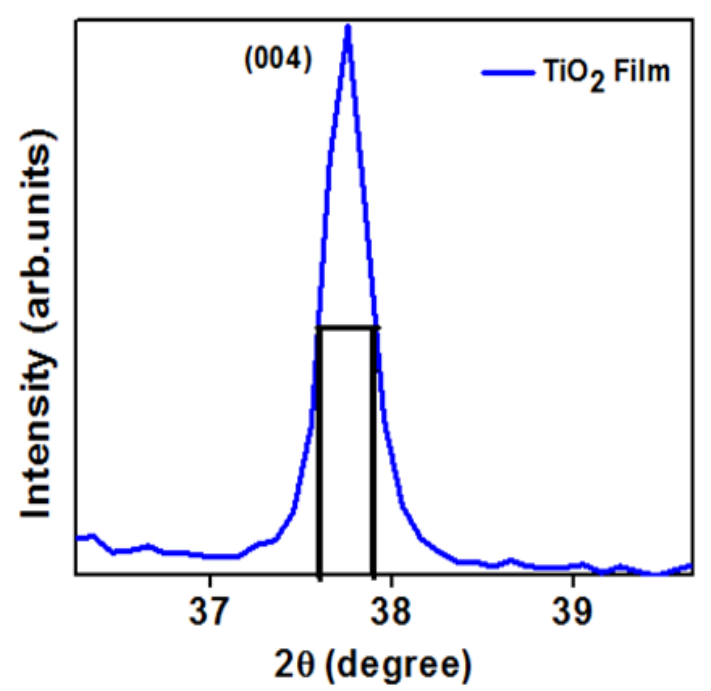

(b)

Fig. 5 (a) XRD pattern of $\mathrm{TiO}_{2}$ film (b) Crystallite size calculation.

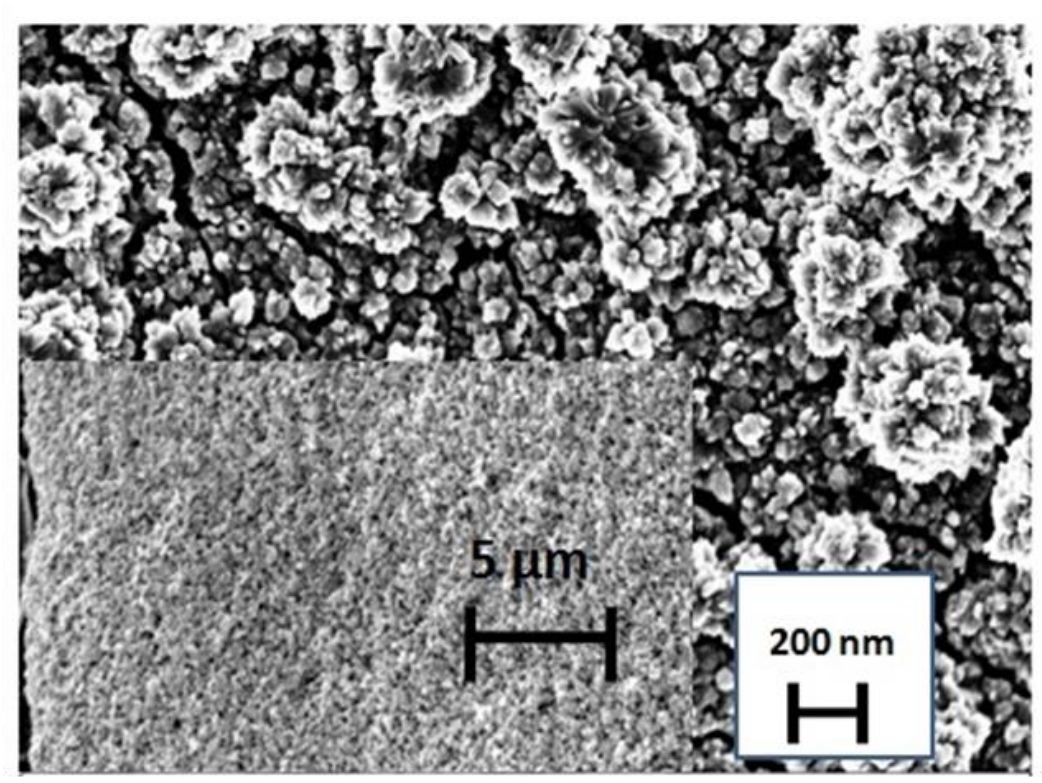

(a)

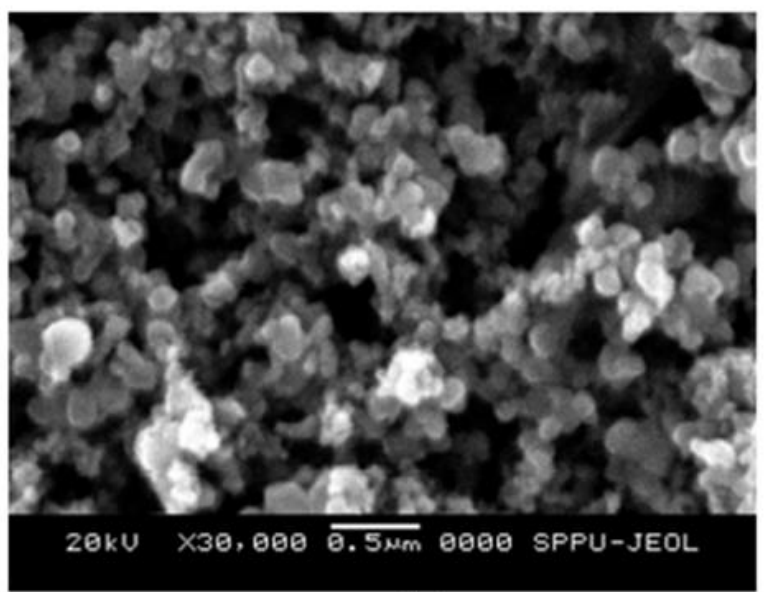

(b)

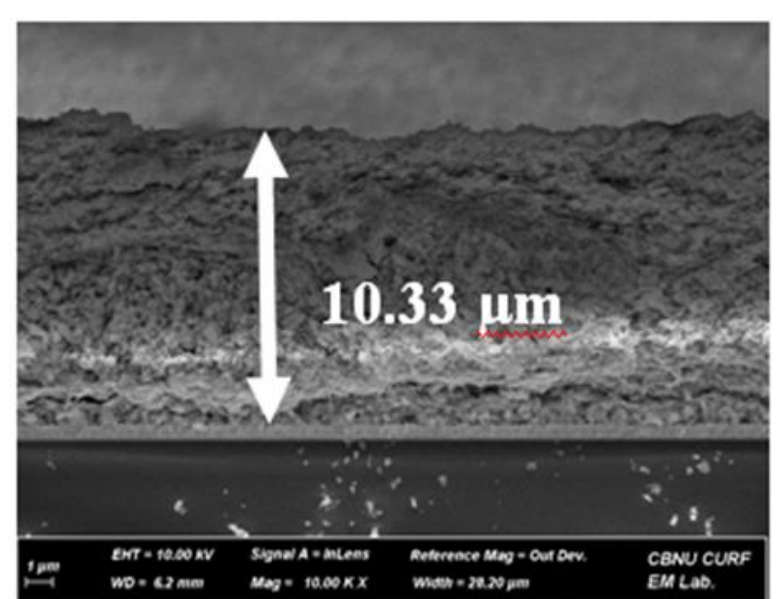

(c)

Fig. 6 Morphology of (a) Compact $\mathrm{TiO}_{2}$ layer, (b) Nanocomposite mesoporous $\mathrm{TiO}_{2}$ and (c) Thickness of the film by FE-SEM technique. 
cases, the electron cloud is highly populated near carbonyl moiety. The DFT analysis revealed the dyes can be functionalized as both donor and $\pi$-linker for photo-sensing activity. The energy values associated with the moiety and its higher HOMO and LUMO levels are presented in the supplementary file vide Fig. S4 and Table S4.

\subsection{Photoanode Characterisation}

\subsubsection{Structural study}

The powder XRD analysis of the mesoporous nanocomposite $\mathrm{TiO}_{2}$ films reveals its anatase phase and crystalline nature. The prototypic peak pattern of (101), (004), and (105) planes, as shown in Fig. 5(a), signifies the percent dominance of anatase form over the rutile phase. This condition is very conducive for the charge carrier's propagation through the photoanode material, which is very advantageous for DSSC application. The crystallite size calculation was done with Full-width half maxima (FWHM) by Scherer's equation ${ }^{[40]}$ as shown in Fig. 5(b) and was found to be $35.53 \mathrm{~nm}$.

\subsubsection{Morphological Analysis}

The elemental and morphological analysis has been carried out with FE-SEM characterization, which shows the mesoporous nature of the $\mathrm{TiO}_{2}$ working electrode's surface. The compact layer $\mathrm{TiO}_{2}$ grew by the chemical bath deposition (CBD) technique exhibit the floral morphology with a highly dense and closely packed layer below the mesoporous layer Fig. 6(a). The transverse section of the film was studied to obtain the thickness of the $10.33 \mu \mathrm{m}$, as shown in Fig. 6(c). The uniformity and porosity are displayed in Fig. 6(b), which is crucial for dye loading. The elemental composition of the $\mathrm{TiO}_{2}$ photoanode has been carried out by Energy Dispersive X-Ray analysis (EDX) presented in supplementary file Fig. S3.

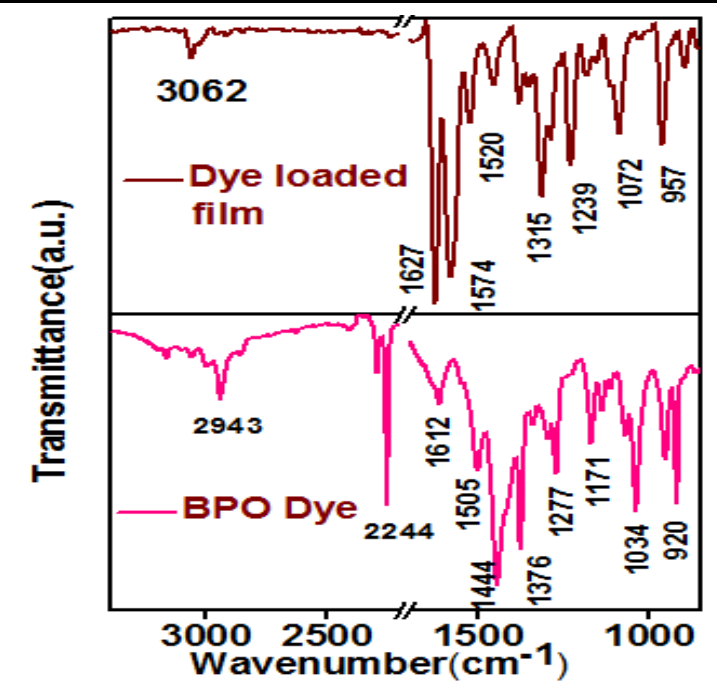

(a)

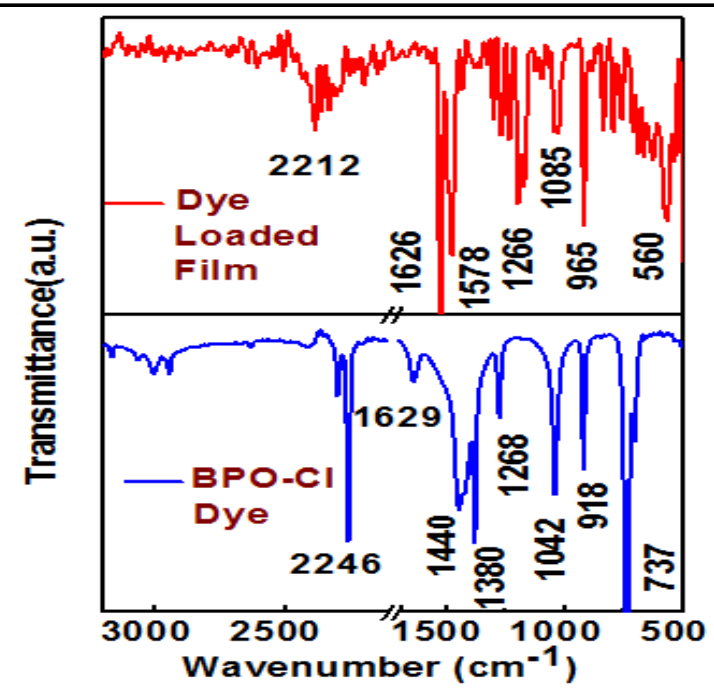

(b)

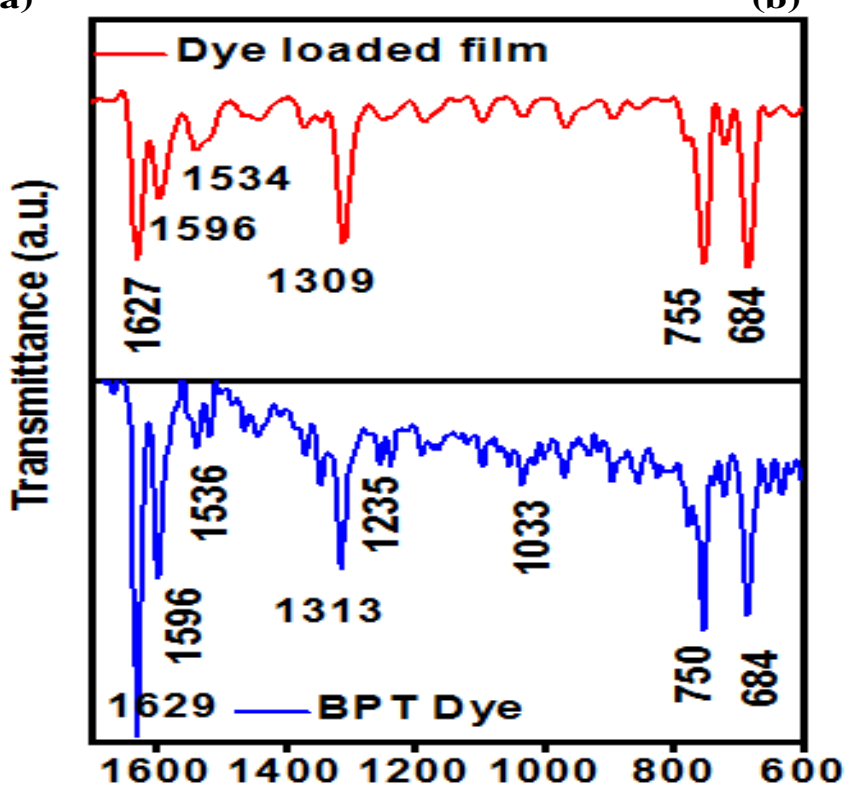

(c)

Fig. 7 FT-IR spectra of basic dye and dye loaded $\mathrm{TiO}_{2}$ film. 


\subsubsection{FTIR study of dye and dye loaded film}

In Fig. 7, the FT-IR spectra of the dye and dye loaded $\mathrm{TiO}_{2}$ films were compared, which shows the bonding interaction between the dye and film along with few minor changes presented in Table 2. In BPO, the intensity of carbonyl stretching frequency in basic dye became highly intense in dye loaded film, confirming $\mathrm{TiO}_{2}$ and carbonyl moiety's bonding interaction with a minute peak shift of $15 \mathrm{~cm}^{-11}$ as depicted in Fig. 7(a). Similarly, in BPO-Cl and BPT, the carbonyl stretching frequency $v_{\mathrm{C}=\mathrm{O}}$ at $1629 \mathrm{~cm}^{-1[41]}$ is shifted to $\sim 1626 \mathrm{~cm}^{-1}$ with an enhanced intensity, which validates the bonding interaction between the photosensitizer and photoanode as shown in Fig. 7(b) and Fig. 7(c). In all the dyes, the stretching frequency nearer to $1277 \mathrm{~cm}^{-1}, 1034 \mathrm{~cm}^{-1}$ in $\mathrm{BPO}$ and $1268 \mathrm{~cm}^{-1}, 1042 \mathrm{~cm}^{-1}$ in BPO-Cl is shifted to $1239 \mathrm{~cm}^{-1}, 1072 \mathrm{~cm}^{-1}$, and $1266 \mathrm{~cm}^{-1}, 1085 \mathrm{~cm}^{-1}$ respectively in dye loaded films ascribed to carbonyl $v_{\mathrm{C}-\mathrm{O}}$ modes, ${ }^{[28]}$ which confirm the added interaction between the dye and $\mathrm{TiO}_{2}$ films. However, in BPT, the peaks near $1235 \mathrm{~cm}^{-1}$ and $1033 \mathrm{~cm}^{-1}$ in the dye molecule are not distinguished in the dye-loaded film probably is the primary reason for lower solar cell efficiency due to the lower extent of dye loading. Peaks near $1376 \mathrm{~cm}^{-1}$, $920 \mathrm{~cm}^{-1}$ in the dye molecule are very prominent in the dye loaded films near $1315 \mathrm{~cm}^{-1}$ and $957 \mathrm{~cm}^{-1}$. The $\mathrm{C}-\mathrm{H}$ vibrational frequency near $2900-3000 \mathrm{~cm}^{-1}$ in the dye molecule is undetectable in the dye-loaded films, whereas only visible in the $\mathrm{BPO}$ molecule. The aromatic protons near $2200-2300 \mathrm{~cm}^{-1}$ in BPO-Cl dye perhaps involved in the internal hydrogen bonding formation and very prominent in the BPO-Cl dye-loaded films, as depicted in Fig. 7(b). In $\mathrm{BPO}-\mathrm{Cl}$, the $v_{\mathrm{C}-\mathrm{Cl}}$ bond frequency was found to be near 737 $\mathrm{cm}^{-1}$. In all the dye loaded films, the peak near $1574 \pm 22$ $\mathrm{cm}^{-1}$ due to $v_{\mathrm{C}=\mathrm{C}}$ stretching frequency is very prominent, confirming the nitrogen atom's involvement in bonding interaction between the dye and photoanode material. Thus, the FT-IR spectrum ensures various functional groups present

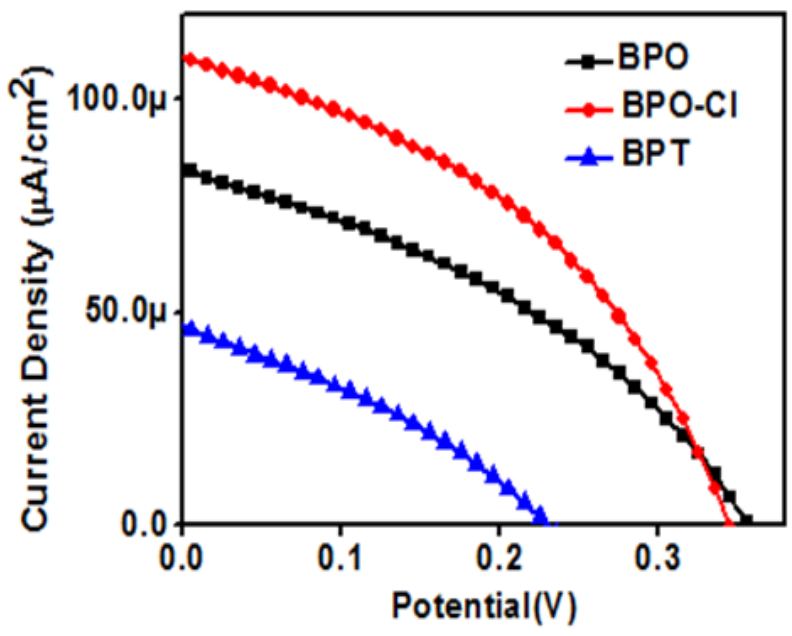

(a) in the dye molecule and its binding mode with the semiconducting metal oxide $\mathrm{TiO}_{2}$ surface.

Table 2. FT-IR frequencies of BPO, BPO-Cl, and BPT after and before dye loading

\begin{tabular}{|c|c|c|c|c|c|c|}
\hline \multirow[t]{2}{*}{$\begin{array}{c}\text { Dye } \\
\text { Name }\end{array}$} & \multicolumn{2}{|c|}{$\begin{array}{l}\mathrm{VC}=0 \\
\left(\mathrm{~cm}^{-1}\right)\end{array}$} & \multicolumn{2}{|c|}{$\begin{array}{c}v \mathrm{~V}=\mathrm{C} \\
\left(\mathrm{cm}^{-1}\right)\end{array}$} & \multicolumn{2}{|c|}{$\begin{array}{c}\text { VC-O } \\
\left(\mathrm{cm}^{-1}\right)\end{array}$} \\
\hline & Dye & $\begin{array}{c}\text { Dye } \\
\text { Loaded } \\
\text { Film }\end{array}$ & Dye & $\begin{array}{c}\text { Dye } \\
\text { Loaded } \\
\text { Film }\end{array}$ & Dye & $\begin{array}{c}\text { Dye } \\
\text { Loaded } \\
\text { Film }\end{array}$ \\
\hline BPO & 1612 & 1627 & 1505 & 1520 & $\begin{array}{l}1277 \\
1034\end{array}$ & $\begin{array}{l}1239 \\
1072\end{array}$ \\
\hline $\mathrm{BPO}-\mathrm{Cl}$ & 1629 & 1626 & - & - & $\begin{array}{l}1268 \\
1042\end{array}$ & $\begin{array}{l}1266 \\
1085\end{array}$ \\
\hline BPT & 1629 & 1627 & 1596 & 1596 & $\begin{array}{l}1235 \\
1033\end{array}$ & $\begin{array}{l}- \\
-\end{array}$ \\
\hline
\end{tabular}

\section{3 Solar cell characterization}

\subsubsection{J-V Characterisation}

The photovoltaic performance of the dyes was studied by $J-V$ measurement using iodine/tri-iodide liquid electrolyte, the platinum counter electrode with solar simulator under 60 $\mathrm{mW} / \mathrm{cm}^{2}$ light intensity. The solar cell characteristic parameters like short-circuit current density $\left(J_{s c}\right)$, open-circuit voltage $\left(V_{o c}\right)$ are presented in Fig. 8 and Table 3. The precursor dyes without any efficient donor and anchoring group can produce an open-circuit voltage ( $V o c$ ) of $0.35 \mathrm{~V}$ with a current density of $85 \mu \mathrm{A} / \mathrm{cm}^{2}$ with a low light intensity $60 \mathrm{~mW} / \mathrm{cm}^{2}$. To study the impact of input power source on these dyes, irradiation of $80 \mathrm{~mW} / \mathrm{cm}^{2}$ power source was introduced, which produces enhanced solar cell characteristics. Nearly fivefold improvement for BPO and $\mathrm{BPO}-\mathrm{Cl}$ dyes in current density is observed, where as for BPT dye, the enhancement is nearly ten times more. We observed a noticeable increment for all the three dyes with enhanced $V_{O C}$ from $0.35 \mathrm{~V}$ to $0.53 \mathrm{~V}$ and $J_{S C}$ from 0.085 $\mathrm{mA} / \mathrm{cm}^{2}$ to $0.44 \mathrm{~mA} / \mathrm{cm}^{2}$ for BPO dye, $V_{O C}$ from $0.34 \mathrm{~V}$ to $0.56 \mathrm{~V}$ and $J_{S C}$ from $0.110 \mathrm{~mA} / \mathrm{cm}^{2}$ to $0.38 \mathrm{~mA} / \mathrm{cm}^{2}$ for

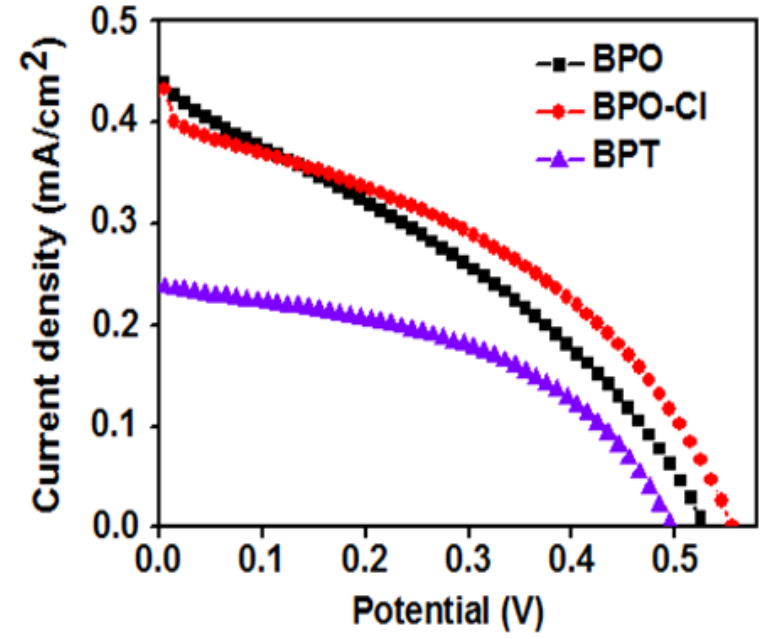

(b)

Fig. 8 Current density-voltage plot at (a) $60 \mathrm{~mW} / \mathrm{cm}^{2}$ (b) $80 \mathrm{~mW} / \mathrm{cm}^{2}$. 
Table 3. Solar cell parameters with a different input power source

$$
60 \mathrm{~mW} / \mathrm{cm}^{2} \quad 80 \mathrm{~mW} / \mathrm{cm}^{2}
$$

\begin{tabular}{ccccc}
\hline Dyes Name & $V_{\text {OOC }}(\mathbf{V})$ & $\begin{array}{c}J_{S C} \\
\left(\mathbf{m A} / \mathbf{c m}^{2}\right)\end{array}$ & $V_{O C}(\mathbf{V})$ & $\begin{array}{c}J_{S C} \\
\left(\mathbf{m A} / \mathbf{c m}^{2}\right)\end{array}$ \\
\hline BPO & 0.35 & 0.085 & 0.53 & 0.440 \\
BPO-Cl & 0.34 & 0.110 & 0.56 & 0.430 \\
BPT & 0.22 & 0.047 & 0.49 & 0.240 \\
\hline
\end{tabular}

BPO-Cl and in BPT dye open circuit voltage increased from $0.22 \mathrm{~V}$ to $0.49 \mathrm{~V}$ and short circuit voltage from 0.047 $\mathrm{mA} / \mathrm{cm}^{2}$ to $0.24 \mathrm{~mA} / \mathrm{cm}^{2}$ with change in input power source from $60 \mathrm{~mW} / \mathrm{cm}^{2}$ to $80 \mathrm{~mW} / \mathrm{cm}^{2}$. Among all the dyes, BPO-Cl possesses the highest $V_{O C}$. Electrochemical impedance spectroscopy is carried out to determine the effect of electrochemical changes in the device behind this enhancement. It is well understood that the increase or decrease in $V_{O C}$ is governed by the potential difference between the quasi-fermi-level $\left(\mathrm{E}_{\mathrm{F}, \mathrm{n}}\right)$ of semiconducting metal oxide and the reduction potential of electrolyte. ${ }^{[42-45]}$ It is directly influenced by the fluctuating electron density of the dye molecule's HOMO and LUMO energy levels displayed in computational studies. Though the exact correlation between $V_{O C}, J_{S C}$, and dye architecture is not detected, the incorporation of chlorine atom greatly impacts solar cell characteristics.

\subsubsection{Electrochemical Impedance Spectroscopy}

Again to unfold the electron transfer in the device between various interfaces, electrochemical impedance spectroscopy (EIS) has been carried out as shown in Figs.9 (b) and (c) under the dark condition at a forward bias of $-0.8 \mathrm{~V}$. All the crucial parameters calculated from Nyquist and Bode plot vide Fig. 9 are presented in Table 4 after fitting with an equivalent circuit diagram, as shown in Fig. 9(a). A glance towards EIS spectra in Fig. 9 (b), Nyquist plot illustrates the smaller semicircle towards higher frequency range produces a resistance between electrolyte and counter electrode interface designated by $R_{C E}$, a greater semicircle in the middle-frequency range termed as recombination resistance ( $\left.R_{R E C}\right)$ at photoanode/dye/electrolyte interface and $R_{S}$ is the total series resistance present in the device due to all the wired connections. As the difference between $R_{R E C}$ and $R_{C E}$ is very high, the first semicircle between the electrolyte and counter electrode interface $\left(R_{C E}\right)$ is not visible as a single semicircle in the middle-frequency range. It is well known that a higher $R_{R E C}$ value produces a lower recombination process and hence enhances the device's Voc. ${ }^{[46]}$ Again, higher the series resistance lowers the solar cell effectiveness. ${ }^{[47]}$

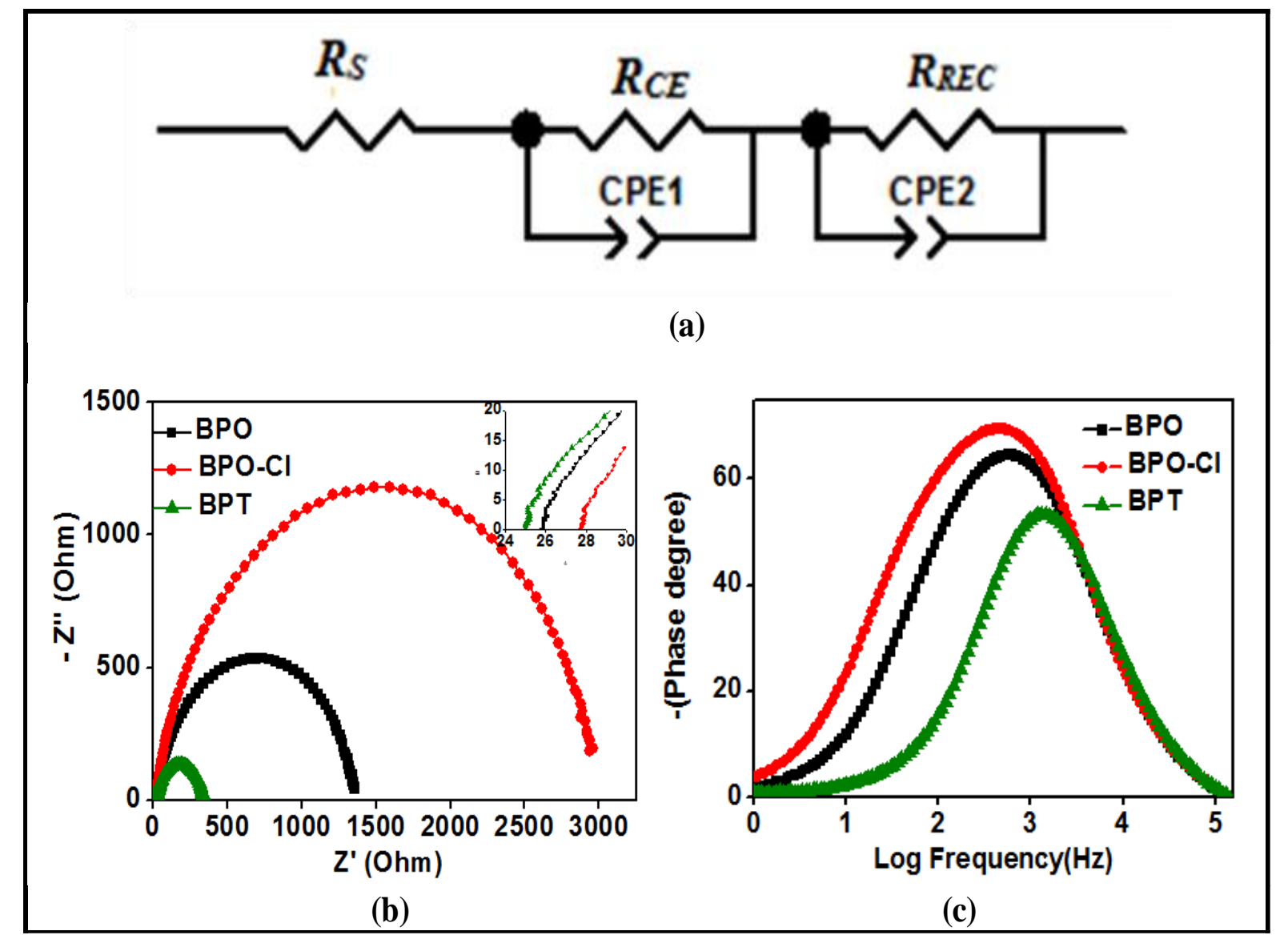

Fig. 9 (a) Equivalent circuit diagram, (b)Nyquist plot, (c) Bode Plot of the BPO, BPO-Cl, and BPT loaded device. 
Table 4. EIS parameters of BPO, BPO-Cl, and BPT dye loaded film.

\begin{tabular}{lllllll}
\hline Dye & $\boldsymbol{R}_{S}(\boldsymbol{\Omega})$ & $\begin{array}{l}\boldsymbol{R}_{C E} \\
(\boldsymbol{\Omega})\end{array}$ & $\boldsymbol{R}_{\boldsymbol{R} E C}(\boldsymbol{\Omega})$ & $\begin{array}{l}\boldsymbol{T}_{\boldsymbol{e}} \\
(\mathbf{m s})\end{array}$ & $\begin{array}{l}\boldsymbol{L n} \\
(\boldsymbol{\mu m})\end{array}$ & $\boldsymbol{\eta}_{\boldsymbol{c}} \%$ \\
\hline BPO & 25.89 & 4.37 & 1332.62 & 0.057 & 17.46 & 99.67 \\
BPO-Cl & 27.74 & 3.94 & 2930.38 & 0.059 & 27.24 & 99.86 \\
BPT & 25.00 & 5.48 & 317.879 & 0.050 & 7.62 & 98.27 \\
\hline
\end{tabular}

Considering the three dyes, the BPO-Cl dye possesses the highest $R_{R E C}$ value. The lowest $R_{C E}$ value gives maximum charge collection efficiency and hence produces maximum $V o c$ in the device. On the contrary, BPT shows the lowest $R_{R E C}$ value and highest $R_{C E}$; therefore, it has a lower open-circuit voltage and low efficiency. The Bode plot in Fig. 9(c) explains the device's electron lifetime, directly affecting the charge collection efficiency and the current density, Jsc, of the device. ${ }^{[47]}$ The electron lifetime can be calculated using the equation $\tau_{\text {eff }}=1 / 2 \pi f$ max, where fmax is the maximum frequency of the Bode plot's intermediate frequency arc and is found to be $0.059 \mathrm{~ms}$ for $\mathrm{BPO}-\mathrm{Cl}, 0.057 \mathrm{~ms}$ for $\mathrm{BPO}$, and lowest for BPT that is $0.050 \mathrm{~ms}$. Again more considerable diffusion length in $\mathrm{BPO}-\mathrm{Cl}$ is also a vital parameter to produce higher charge collection efficiency $\left(\eta_{c c}\right)$ in the device, which is directly related to the device's $J s c$. A trend of higher $V o c$ and $J s c$ in BPO-Cl followed by BPO and then BPT is fine-tuned with diffusion length and hence charge collection efficiency in the device. Thus all the EIS parameters are fine-tuned with solar cell entities. Higher Voc and $J_{S C}$ in BPO-Cl dye are credited to lesser recombinations, higher electron lifetime, and high charge collection efficiency in the device. All the formulae required to calculate the EIS parameters are as per the literature. ${ }^{[48-50]}$ It is clear from EIS analysis that the simple incorporation of chlorine in the BPO skeleton reduces recombination chances a lot as recombination resistance becomes double in BPO-Cl dye, thus produces more $V_{O C}$ and $J_{S C}$ in the device. Hence, tailoring of efficient anchoring and donating groups will enhance the solar cell efficiency to many folds.

In this investigation, the electron percolation and recombination mechanism in the DSSC device are schematically presented in Fig. 10. A glance at evaluating the physicochemical properties of photosensitizers on solar cell effectiveness is illustrated here through the pictorial form. When photosensitizers (BPO, BPO-Cl, and BPT) are exposed to solar radiation; they absorb the photon of light and excited from the ground state $\left(\mathrm{S}^{0} / \mathrm{S}^{+}\right)$to the excited state $\left(\mathrm{S}^{+} / \mathrm{S}^{*}\right)$ where the excited dye molecule injects the electrons to the conduction band (CB) of $\mathrm{TiO}_{2}$ semiconducting metal oxide coated on fluorine-doped tin oxide (FTO) substrate ${ }^{[51]}$ As the HOMO level is below the work function of electrolyte; they get adequate driving force for dye regeneration. The LUMO level above the $\mathrm{CB}$ provides good electron injection efficiency. ${ }^{[52]}$ Further, the planar shape of the moiety percolates the electron through the aromatic ring of the

\section{photosensitizers.}

Moreover, the chlorine atom addition reduces the recombination by reducing the HOMO-LUMO gap, as reflected in Fig. 3, which agrees with the literature. ${ }^{[39]}$ Again, these electrons are transferred from $\mathrm{TiO}_{2}$ photoanode to platinum counter electrode $(\mathrm{Pt})$ and further reduces the oxidized dye molecule by iodine/triiodide electrolyte. Along with this, some recombinations are also taking place at several interfaces in the device, which can also be controlled by modifying the photosensitizer behavior and device fabrication techniques.

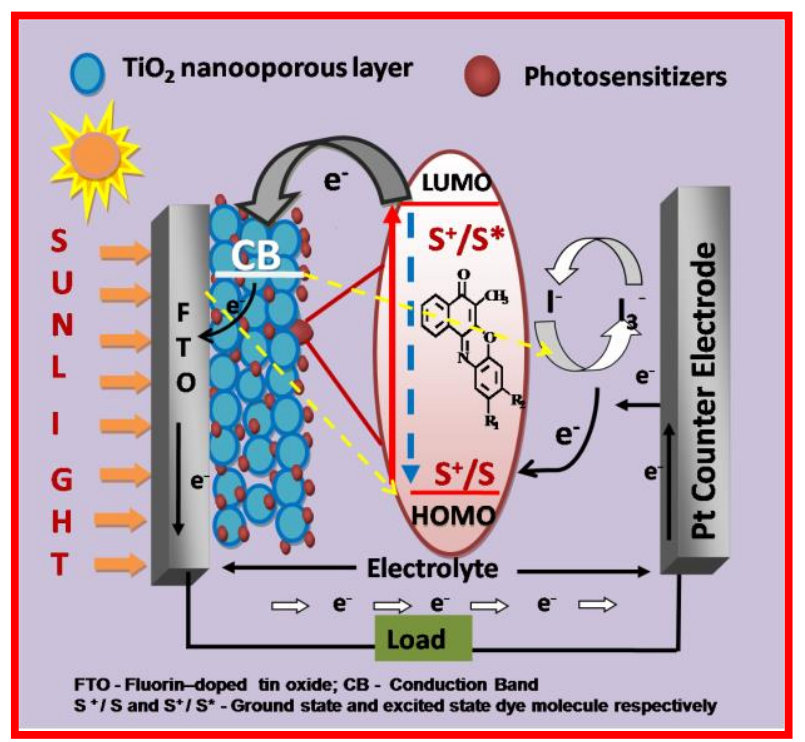

Fig. 10 Schematic presentation of DSSC device with Benzo $[\alpha]$ phenoxazine moiety as a photosensitizer with electron percolation and recombination paths.

\section{Conclusions}

A detailed evaluation of physicochemical properties of three benzo[a]phenoxazine dyes was studied and implemented as photosensitizers successfully. The application of benzo[ $\alpha]$ phenoxazine moiety as a photosensitizer was demonstrated through a DSSC device with optical, electrochemical, structural, and solar cell (current-density) characterizations. The unsubstituted benzo $[\alpha]$ phenoxazine moiety produces noticeable $V_{O C}$. Even the open-circuit voltage $\left(V_{O C}\right)$ is good enough to glow the small LEDs efficiently. Hence, tailoring an efficient D/A group on benzo[a]phenoxazine produces more solar cell efficiency than the phenoxazine precursors. A simple chlorine substitution on the benzo[ $\alpha]$ phenoxazine skeleton reduces the recombination more than twice in BPO-Cl. It enhances the open-circuit voltage $\left(V_{O C}\right)$ as well as current density. Thus a targeted D/A group will generate enhanced solar cell output. With the increase in incident light source, there is a steady enhancement of $V_{O C}$ and $J_{S C}$ in the device, which is very conducive for DSSC fabrication. Out of this experiment, it is evident that benzo[ $\alpha]$ phenoxazines have the inherent potential to become a photosensitizer and an efficient precursor for dyes. Resourceful dyes can be obtained with 
adequate D/A substitution on the BPO template at targeted sites. Moreover, the BPO-Cl loaded device's effectiveness is credited to its proximity of LUMO level to the conduction band of $\mathrm{TiO}_{2}$ semiconducting metal oxide, reduced recombination, high diffusion length, and comparatively longer electron lifetime. So tailoring efficient donor and anchoring moiety to the benzo[ $\alpha]$ phenoxazine template can be used as a new platform for producing useful photosensitizers.

\section{Acknowledgments}

We acknowledge the various instrumental support from the Department of Physics, and the Department of Chemistry Savitribai Phule Pune University. We also grateful to the Department of Science and Technology, Government of India, for financial support vide Sanction order DST/TMD/SERI/S173(G). PB is very thankful to the Department of Higher Education, Science and Technology and Biotechnology, Govt. of West Bengal, India, for providing financial assistance to carry out this research work [vide sanction order no. 78(Sanc.)/ST/P/S\&T/6G-1/2018 dated 31.01.2019 and project no. GAP-225612].

\section{Supporting information}

Applicable

\section{Conflict of interest}

There are no conflicts to declare.

\section{References}

[1] B. O'regan and M. Grätzel, Nature, 1991, 353, 737-740, doi: 10.1038/353737a0.

[2] Q. Chang, H. Chen. J. Yuan, Y. Hu, J. Hai, W. Liu, F. Cai, J. Hong, X. Xiao and Y. Zou, J. Energy Chem., 2020, 51, 7-13, doi: 10.1016/j.jechem.2020.03.036.

[3] A. A. Yadav, V. C. Lokhande, R. N. Bulakhe and C. D. Lokhande, Microchim. Acta, 2017, 184, 3713-3720, 10.1007/s00604-017-2364-3.

[4] S. Patil, R. Bulakhe, P. Deshmukh, N. Shinde and C. Lokhande, Sens. Actuators A Phys., 2013, 201, 387-394, doi: 10.1016/j.sna.2013.07.019.

[5] R. N. Bulakhe, S. A. Arote, B. Kwon and S. Park, I. In, Mater. Today Chem., 2020, 15, 100210, doi: 10.1016/j.mtchem.2019.100210.

[6] G. A. Sewvandi, C. Chen, T. Ishii, T. Kusunose, Y. Tanaka, S. Nakanishi, and Q. Feng, J. Phys. Chem. C, 2014,118, 20184-20192, doi: 10.1021/jp5058397.

[7] A. Mishra, M. K. Fischer and P. Bäuerle, Angew. Chem. Int. Ed., 2009, 48, 2474-2499, doi: 10.1002/anie.200804709.

[8] N. Mariotti, M. Bonomo, L. Fagiolari, N. Barbero, C. Gerbaldi, F. Bella and C. Barolo, Green Chem., 2020, 22, 7168-7218, doi:10.1039/D0GC01148G.
[9] E. Guillen, F. Casanueva and J. A. Anta, J. Photochem. Photobiol. A, 2008, 200, 364-370. doi: 10.1016/j.jphotochem.2008.08.015.

[10] G. Sharma, P. Balraju, M. Kumar and M. Roy, Mater. Sci. Eng. B, 2009, 162, 32-39, doi: 10.1016/j.mseb.2009.01.033. [11] R. Sánchez-de-Armas, M. A. San Miguel, J. Oviedo and J. F. Sanz, Phys. Chem. Chem. Phys., 2012, 14, 225-233, doi: 10.1039/C1CP22058F.

[12] K. Hara, Z. Wang, T. Sato, A. Furube, R. Katoh, H. Sugihara, Y. Dan-oh, C. Kasada, A. Shinpo and S. Suga, J. Phys. Chem. B, 2005, 109, 15476-15482, doi:10.1021/jp0518557.

[13] M. Lončarić, D. Gašo-Sokač, S. Jokić and M. Molnar, Biomolecules, 2020, 10, 151, doi: 10.3390/biom10010151.

[14] A. B. Athanas, S. Thangaraj and S. Kalaiyar, Chem. Phy. Lett., 2018, 699, 32-39, doi: 10.1016/j.cplett.2018.03.033.

[15] Y. Shi R. B. M. Hill, J. Yum, A. Dualeh, S. Barlow, M. Grätzel, S. R. Marder, and M. K.Nazeeruddin, Angew. Chem. Int. Ed., 2011, 50, 6619-6621, doi:10.1002/anie.201101362.

[16] X. Wang, J. Xu, M. Li, D. Fang, B. Chen, L. Wang and W. Xu, RSC Adv., 2013, 3, 5227-5237, doi: 10.1039/C3RA40193F.

[17]Y. Chen, V. Nguyen, H. Chou, Y. S. Tingare, T. Wei, and C. Yeh, ACS Appl. Energy Mater., 2020, 3, 5479-5486, doi: 10.1021/acsaem.0c00464.

[18] W.J. Fan, W. Fan, Y. Chang, J. Zhao, Z. Xu, D. Tan, and Y. Chen, New J. Chem., 2018, 42, 20163-20170, doi:10.1039/C8NJ03592J

[19] S. Kolemen, O. A. Bozdemir, Y. Cakmak, G. Barin, S. Erten-Ela, M. Marszalek, J. Yum, S. M. Zakeeruddin, M. K. Nazeeruddin, M. Grätzel and E. U. Akkaya, Chem. Sci., 2011, 2, 949-954, doi: 10.1039/C0SC00649A.

[20] H. Klfout, A. Stewart, M. Elkhalifa and H. He, ACS Appl. Mater. Interfaces, 2017, 9, 39873-39889, doi: 10.1021/acsami.7b07688.

[21] V. Saravanan, S. Ganesan and P. Rajakumar, RSC Adv., 2020, 10, 18390-18399, doi: 10.1039/D0RA01672A.

[22] F. A. Schröder, J. M. Cole, P. G. Waddell and S. McKechnie, $A d v$. Energy Mater, $\quad 2015, \quad 5, \quad 1401728$, doi: 10.1002/aenm.201570047.

[23] H. Tian, X. Yang, R. Chen, A. Hagfeldt and L. Sun, Energy Environm. Sci., 2009, 2, 674-677, doi:10.1039/B901238A.

[24] H. Tan, C. Pan, G Wang, Y. Wu, Y. Zhang, G. Yu, and M. Zhang, Dyes Pigm., 2014, 101, 67-73, doi:10.1016/j.dyepig.2013.09.039.

[25] W. Wu, J. Yang, J. Hua, J. Tang, L. Zhang, Y. Long and H. Tian, J. Mat. Chem., 2010, 20, 1772-1779, doi:10.1039/B918282A.

[26] H. Tian, I. Bora, X. Jiang, E. Gabrielsson, K. M. Karlsson, A. Hagfeldt and L. Sun, J. Mater. Chem., 2011, 21, 
12462-12472, doi:10.1039/C1JM12071A.

[27] S. Bhand, D. Chadar, K. Pawar, M. Naushad, H. Pathan and S. Salunke-Gawali, J. Mater. Sci: Mater. Electron., 2018, 29, 1034-1041, doi:10.1007/s10854-017-8003-2.

[28] D. Chadar, S. S. Rao, A. Khan, S. P. Gejji, K. Sideeq Bhat, T. Weyhermüller and S. Salunke-Gawali, RSC Adv., 2015, 5, 57917-57929, doi:10.1039/C5RA08496B.

[29] S. S. Khadtare, A. P. Ware, S. Salunke-Gawali, S. R. Jadkar, S. S. Pingale and H. M. Pathan, RSC Adv., 2015, 5, 17647-17652, doi: 10.1039/C4RA14620D.

[30] G. P. Sarmiento, F. Martini, R. G. Vitale, L. E. Fabian, J. Afeltra, D. Vega, G. Y. Moltrasio and A. G. Moglioni, Arab. J. Chem., 2019, 12, 21-32, doi:10.1016/j.arabjc.2017.11.019.

[31] L. J. Farrugia, J. Appl. Cryst., 2012, 45, 849-854, doi:10.1107/S0021889812029111.

[32] C. F. Macrae, I. J. Bruno, J. A. Chisholm, P. R. Edgington, P. McCabe, E. Pidcock, L. Rodriguez-Monge, R. Taylor, J. van de Streek and P. A. Wood, J. Appl. Cryst., 2008, 41, 466-470, doi:10.1107/S0021889807067908.

[33] S. K. Saha, A. Hens, N. C. Murmu and P. Banerjee, J. Mol. Liq., 2016, 215, 486-495, doi:10.1016/j.molliq.2016.01.024.

[34] P. Ghosh, B. G. Roy, S. Jana, S. K. Mukhopadhyay and P. Banerjee, Phys. Chem. Chem. Phys., 2015, 17, 20288-20295, doi:10.1039/C5CP02525G

[35] P. Ghosh and P. Banerjee, Phys. Chem. Chem. Phys., 2016 18, 22805-22815, doi:10.1039/C6CP01620K

[36] R. Ahlrichs, M. Bär, M. Häser, H. Horn and C. Kölmel, Chem. Phys. Lett., 1989, 162, 165-169, doi:10.1016/0009-2614(89)85118-8.

[37] A. Schäfer, H. Horn and R. Ahlrichs, J. Chem. Phys., 1992, 97, 2571-2577, doi: 10.1063/1.463096.

[38] G. Boschloo and A. Hagfeldt, Acc. Chem. Res., 2009, 42, 1819-1826, doi: 10.1021/ar900138m.

[39] R. Zhou, J. Feng, X. Peng, L. Zhong and R. Sun, J. Energy Chem., 2020, doi: 10.1016/j.jechem.2019.09.010.

[40] P. M. Kibasomba, S. Dhlamini, M. Maaza, C. P. Liu, M. M. Rashad, D. A. Rayan and B.W. Mwakikung, Results Phys., 2018, 9, 628-635, doi:10.1016/j.rinp.2018.03.008.

[41] D. Chadar, D. Chakravarty, D. N.Lande, S.P. Gejji, S. Sahoo and S. Salunke-Gawali, J. Mol. Struct., 2017, 1149, 84-91, doi: 10.1016/j. molstruc.2017.07.091.

[42] S. Huang, G. Schlichthörl, A. Nozik, M. Grätzel and A. Frank, J. Phys. Chem. B, 1997, 101, 2576-2582, doi:10.1021/jp962377q2.

[43] H. Paulsson, L. Kloo, A. Hagfeldt and G. Boschloo, J. Electroanal. Chem., 2006, 586, 56-61, doi:10.1016/j.jelechem.2005.09.011.

[44] T. Privalov, G. Boschloo, A. Hagfeldt, P. H. Svensson and L. Kloo, J. Phys. Chem. C, 2009, 113, 783-790, doi:10.1021/jp810201c.

[45] S. Borbón, S. Lugo, D. Pourjafari, N. P. Aguilar, G. Oskam, and I. López, ACS Omega, 2020, 5, 10977-10986, doi:10.1021/acsomega.0c00794.

[46] T. Zhang, C. An, Q. Lv, J. Qin, Y. Cui, Z. Zheng, B. Xu, S. Zhang, J. Zhang, C. He and J.Hou, J. Energy Chem., 59, 30-37, doi:10.1016/j.jechem.2020.11.021.

[47] M. Adachi, M. Sakamoto, J. Jiu, Y. Ogata and S. Isoda, J. Phys. Chem. B, 2006, 110, 13872-13880, doi:10.1021/jp061693u.

[48] L. Zhang, X. Yang, W. Wang, G. G. Gurzadyan, J. Li, X. Li, J. An, Z Yu, H. Wang, B Cai, A. Hagfeldt and L. Sun, ACS Energy Lett., 2019, 4, 943-951, doi:10.1021/acsenergylett.9b00141.

[49] C. V. Jagtap, V. S. Kadam, S. R. Jadkar and H. M. Pathan, ES Energy Environ., 2019, 3, 60-67, doi:10.30919/esee8c220.

[50] A. R. Bredar, A. L. Chown, A. R. Burton and B. H. Farnum, ACS Appl. Energy Mater. 2020, 3, 66-98, doi:10.1021/acsaem.9b01965.

[51] D. Cahen, G. Hodes, M. Grätzel, J. F. Guillemoles and I. Riess, J. Phys. Chem. B, 2000, 104, 2053-2059, doi:10.1021/jp993187t.

[52] D. P. Hagberg, T. Marinado, K. M. Karlsson, K. Nonomura, P. Qin, G. Boschloo, T. Brinck, A. Hagfeldt, and L. Sun, J. Org. Chem., 2007, 72, 9550-9556, doi:10.1021/jo701592x.

\section{Author information}

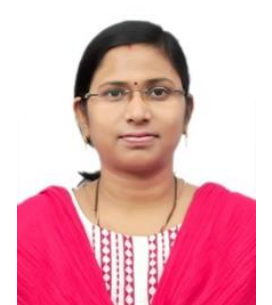

Suprabha Soumya Sahoo, perceiving her Ph.D. under the supervision of Professor Sunita Salunke - Gawali and Dr. Habib M. Pathan at Department of Chemistry in Savitribai Phule Pune University, Pune (India). She was awarded her master's degree in Organic Chemistry in 2012 from the same university and did her Bachelors of Education (B.Ed.) in 2013. Her research interests are synthesizing and engineering photosensitizers, preparing various photoanodes for dye-sensitized solar cells, and device fabrication techniques.

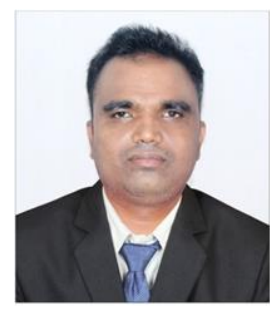

Dattatray Ashruba Chadar completed his M.Sc. in Analytical Chemistry at the Department of Chemistry, Dr. Babasaheb Ambedkar Marathawada University, Aurangabad (India). He received his Ph.D. in Chemistry from the Department of Chemistry, Savitribai Phule Pune University, India, under the supervision of Professor Sunita Salunke-Gawali. The 
topic of his Ph.D. study was on synthesis, characterization, metal complexation, and biological activity of amino/imino derivatives of Vitamin K3 (2-Methyl-1,4-naphthoquinone). He worked as a Research Associate in CSIR-Central Salt and Marine Chemical Research Institute, Bhavnagar in India. His research interest mainly focuses on coordination chemistry, organic synthesis, and carbohydrate-based biopolymers.

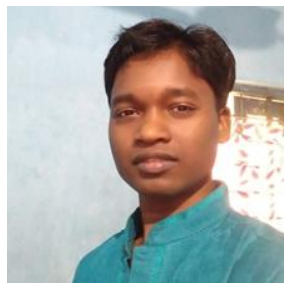

Manilal Murmu received his M.Sc. degree in Chemistry in 2014 from Visva Bharat University, Santiniketan, Bolpur, West Bengal, India. At present, he is pursuing a Ph.D. in Chemical Sciences under the Academy of Scientific and Innovative Research (AcSIR) under the joint supervision of Dr. Priyabrata Banerjee, Principal Scientist, and Dr. Naresh Chandra Murmu, Senior Principal Scientist, Surface Engineering and Tribology Group, CSIR-Central Mechanical Engineering Research Institute (CMERI), Durgapur. His research is primarily focused on developing and characterizing organic corrosion inhibitors and anticorrosive coating to protect metallic materials. His research is also in the field of theoretical and computational chemistry.

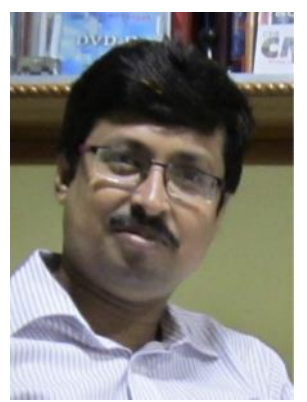

Priyabrata Banerjee is a Principal Scientist at Surface Engineering \& Tribology Group, CSIR-Central Mechanical Engineering Research Institute (CMERI), Durgapur, 713209, West Bengal, India \& Associate Professor at Academy of Scientific and Innovative Research (AcSIR), CSIR-HRDC Campus, Ghaziabad, 201002, Uttar Pradesh, India. Dr. Banerjee received his Ph.D. degree in 2007 from the Indian Association for Cultivation of Science, Jadavpur, Kolkata, India. He did his Post Doctoral research at Max Planck Institute for Bio-Inorganic Chemistry, Müelheim, Germany, during 2007-2010. He was a visiting fellow at the University of Water Science, HTWD, Dresden, Germany, and presently he has been selected as CSIR-Raman Research Fellow (2019-2020) at Ghent University, Belgium. He has published 104 research papers (3711 citations) in several International SCI journals (h-index: 33, i-index: 78), 10 book chapters, 10 magazines, and several review articles in world reputed forums. His current research interest broadly covers selective bio-relevant cation-anion detection, corrosion science, theoretical and computational chemistry, solid waste management, wastewater treatment, Metal mediated C-heteroatom bond fusion metal-organic complexes, and their hitherto unexplored radical chemistry development.

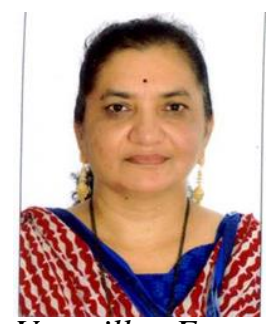

Sunita Salunke-Gawali, received her M.Sc. (1993) in Inorganic Chemistry and Ph.D. (1999) from Pune University. As a professional experience she worked as Post-doctoral Research Associate at Laboratoire de Magnétisme et d'Optique, Versailles France (Prof. F. Varret, 2001-2002), Department of Chemistry, IIT Bombay, India (Prof. C. P. Rao, 2002 and 2004), Universidade do Porto, Portugal, supervised by Prof. Eulália Pereira (2004-2007) and Max-Planck-Institut für Bioanorganische Chemie, Mülheim an der Ruhr, Germany (Dr. Eckhard Bill, 2007-2008). She joined as a Reader in the Department of Chemistry, Savitribai Phule Pune University, in 2008, where she serves now as a Professor. Her research interests include coordination and bioorganic Chemistry of naphthoquinone ligands, developing photosensitizer for DSSC, HPLC method development for anticancer drugs, and separation of tautomers, chemosensors, and metallosurfactants. She is the author of more than 87 articles in international journals.

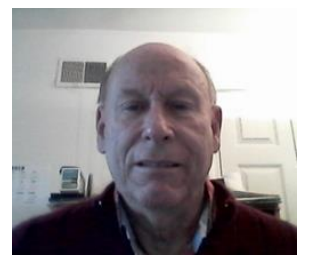

Ray J. Butcher, Born in Greymouth, New Zealand, on 11th October 1945. Educated at the University of Canterbury in New Zealand. Appointed Instructor 1974-76 at the University of Virginia, Charlottesville, Virginia and Post-Doctoral Fellow 1976-77, Georgetown University, Washington D.C. Joined the Chemistry Department at Howard University as an Assistant Professor in 1977 and promoted to Associate Professor in 1982 and Professor in 1997. Has had many visiting appointments, including a Navy Distinguished Summer Faculty Fellow at the Naval Research Laboratory, a Visiting Senior Scientist at Los Alamos National Laboratory, Los Alamos, a distinguished visiting professor at the Indian Institute of Technology Bombay, in Mumbai, India. Has held two Fulbright-Nehru Fellowships to India (1989, 2009) and a Distinguished Chair Fulbright-Nehru Fellowship to India (2019). Was elected a Fellow of the Royal Society of Chemists (FRSC) in 2018. Has published over 1340 papers in refereed journals since 1975.

Publisher's Note: Engineered Science Publisher remains neutral with regard to jurisdictional claims in published maps itand instutional affiliations. 